\title{
Complex Pathways Towards Emergent Pastoral Settlements: New Research on the Bronze Age Xindian Culture of Northwest China
}

\author{
Yitzchak Jaffe ${ }^{1} \cdot$ Anke Hein $^{2} \cdot$ Andrew Womack $^{3} \cdot$ Katherine Brunson $^{4}$. \\ Jade d'Alpoim Guedes ${ }^{5}$. Rongzhen Guo ${ }^{6}$. Jing Zhou' ${ }^{7}$ Jada Ko ${ }^{8}$. \\ Xiaohong Wu ${ }^{9}$. Hui Wang ${ }^{10} \cdot$ Shuicheng $\mathrm{Li}^{11} \cdot$ Rowan Flad $^{8}$
}

Accepted: 27 October 2021 / Published online: 1 January 2022

(c) The Author(s) 2022

\begin{abstract}
The Xindian culture of northwest China has been seen as a prototypical example of a transition toward pastoralism, resulting in part from environmental changes that started around 4000 years ago. To date, there has been little available residential data to document how and whether subsistence strategies and community organization in northwest China changed following or in association with documented environmental changes. The Tao River Archaeology Project is a collaborative effort aimed at gathering robust archaeological information to solidify our baseline understanding of economic, technological, and social practices in the third through early first millennia BC. Here we present data from two Xindian culture residential sites, and propose that rather than a total transition to nomadic pastoralism-as it is often reconstructed - the Xindian culture reflects a prolonged period of complex transition in cultural traditions and subsistence practices. In fact, communities maintained elements of earlier cultivation and animal-foddering systems, selectively incorporating new plants and animals into their repertoire. These locally-specific strategies were employed to negotiate ever-changing environmental and social conditions in the region of developing 'proto-Silk Road' interregional interactions.
\end{abstract}

Keywords Bronze Age $\cdot$ Northwest China $\cdot$ Xindian culture $\cdot$ Agro-Pastoralism · Paleoclimate

\section{摘要}

中国西北地区的辛店文化一直被认为是农耕社会转型为游牧社会的典型案 例。其转型原因部分源于距今4000年前剧烈的自然环境变化。迄今为止, 反映 这一地区生计和社会组织是否以及如何随着环境变化而变化相关的聚落考古 资料胗䇣无几。中美联合洮河考古项目主要通过系统性搜集考古信息, 巩固学

Rowan Flad

rflad@fas.harvard.edu

Extended author information available on the last page of the article 
界对公元前第三千年至公元前第一千年的早期经济、技术和社会行为的基本 认识。本文在具体观察两个辛店考古文化的聚落遗址(辛店遗址于灰嘴山遗址) 资料后，发现辛店文化并非完全转化为游牧社会的简单的过渡期文化，而是包 含了一个长期复杂的文化传统和生计模式的转变。事实上, 辛店社会的农业在 保留了早期传统作物和动物饲料栽培小米, 猪等的基础上，选择性的纳入了新 的动植物，比如羊牛麦子等。笔者认为，这种具有地方特色的策略是為了适应 這一地区在剧烈的区域互动(原始丝绸之路)中不断变化的自然环境和社会条件 而形成的.

\section{Introduction}

The turn of the third to second millennia BC (i.e., c. $4000 \mathrm{BP}$ ) is a time when the western regions of the area currently within the People's Republic of China witnessed a number of radical changes in patterns of subsistence, organization of communities and general ways of life (see Womack et al., 2017; Yang et al., 2019a, 2019 b). A network of 'proto-Silk Roads' that began to emerge in the preceding millennium involved trade, exchange, and population movements and resulted in the gradual introduction of new technologies-including metallurgy and West Asian or Central Asian domesticates, such as wheat, barley, caprines, cattle and eventually horses-alongside the movement of ancient people (recent studies and summaries of these processes can be found in: Brunson et al., 2020; d'Alpoim Guedes \& Bocinsky, 2018; Dong et al., 2017; Flad, 2017; Han, 2012; Jaang, 2015; Jaffe \& Flad, 2018; Leipe et al., 2019; Lin, 2016; Lister et al., 2018; Liu et al., 2017; Long et al., 2018; Mei et al., 2015; Ventresca Miller \& Makarewicz, 2019; Womack et al., 2021, among others). An apparent confluence of social and cultural developments coupled with the onset of cooler and drier conditions, sometimes termed the ' 4.2 k BP event', has led scholars to assign a pivotal role to the effects of climate change on these processes across this broad region (e.g. An et al., 2005; Liu \& Feng, 2012; Wu \& Liu, 2004; and see Jaffe et al., 2020).

On the macroscale, there is considerable evidence that climate change corresponded to significant changes in human behavior. On the Tibetan plateau, for example, computational climatic models show that related climate changes may have led to a major transition in subsistence regimes that resulted in a shift from millet farming to more cold-adapted crops like barley (d'Alpoim Guedes, 2016; d'Alpoim Guedes et al., 2013, 2015). Climate change does not impact all regions of the globe in a homogeneous fashion, and the integration of environmental and archaeological studies can provide data about not only the types of challenges that people faced but how they reacted to these in specific local contexts (Contreras, 2016; d'Alpoim Guedes et al., 2016a, 2016b; Hudson et al., 2012; Haldon et al., 2018; Kintigh et al., 2014). In lower altitude regions of the loess plateau off the Tibetan plateau it is unclear what impacts, if any, environmental change had on subsistence and society, due to a lack of data on human practices and organization from excavated settlements (Jaffe \& Hein, 2020).

One proposed set of changes is a possible shift to increasingly pastoralist subsistence practices, a process that relates to the important issue of emergent 
pastoralism in many global contexts (Frachetti, 2012; Harris, 1996; Honeychurch \& Makarewicz, 2016; Marshall et al., 2018; Spengler \& Mueller, 2019). In what today constitutes the western loess plateau and Tao river valley, some scholars propose a large-scale and speedy transition from mostly sedentary agricultural economies to mobile pastoral subsistence systems (e.g. Dong et al., 2013; Liu and Feng, 2012; Wagner et al, 2013; Wu \& Liu, 2004). To date, however, there is relatively sparse residential, archaeobotanical and zooarchaeological data on how people adapted their cultural and subsistence practices in specific regions within the wide area of northern China (Jaffe \& Hein, 2020). In this paper, we provide new data from two residential settlements dating to the cultural phase after a transition attributed, at least in part, to environmental change. We argue that rather than changing their subsistence practices completely, people maintained elements of earlier cultivation and animal foddering systems, selectively incorporating new plants and animals into their repertoire. These results fit a pattern observed in other contexts of locally-specific strategies that incorporate pastoral and agrarian practices in ways that are appropriate to specific changing environmental and socio-political conditions (e.g. Brunson et al., 2016; Hermes et al., 2019; Spengler et al., 2014; Ventresca Miller \& Makarewicz, 2019; Ventresca Miller et al., 2020).

\section{Reassessing Human-Environment Interaction Along the Proto-Silk Road}

The developing proto-Silk Road networks loosely tied together communities that were widely spread across different environments: from the arid deserts of the Gobi and nearby parts of the Hexi Corridor, to the more arable river-valleys of parts of Gansu and Qinghai, where successors to those who created the painted pottery traditions of the Majiayao 马家窑 (c. 3300-2650 BC/5250-4600 BP), Banshan 半山 (c. 2800-2300 BC/4750-4250 BP) and Machang 马厂 (c. 2300-1950 BC/4250-3900 BP) archaeological cultures of the third millennium BC lived in settlements associated with the Qijia culture 齐家 (c. 2200-1500 BC/4150-3450 BP) (see Table 1

Table 1 Major archaeological cultures in Gansu and their dates (after Jaffe \& Flad, 2018; Li et al., 2010; Wang, 2012)

\begin{tabular}{lll}
\hline Culture phase & Approximate dates BC & Approximate dates BP \\
\hline Yangshao & $5000-3000$ & $7000-5000$ \\
Majiayao & $3300-2650$ & $5250-4600$ \\
Banshan & $2800-2300$ & $4750-4250$ \\
Machang & $2300-1950$ & $4250-3900$ \\
Qijia & $2200-1500$ & $4150-3450$ \\
Siba & $1950-1550$ & $3900-3500$ \\
Kayue & $1800-1500$ & $3750-3450$ \\
Xindian & $1600-600$ & $3550-2550$ \\
Siwa & $1300-500$ & $3250-2450$ \\
\hline
\end{tabular}


with associated dates). The widespread Qijia culture was characterized by agricultural communities who adopted new technologies and set the stage for an increasingly interconnected world in Bronze Age North China (see Dong et al., 2017; Jaang, 2015; Jaffe \& Flad, 2018; Lin, 2016; Womack et al., 2017, 2019a). Qijia cultural influence was widespread, but it is the next chronological stage when the development of a variety of social practices and cultural components is seen to have contributed to the increasingly complex origin of Chinese civilization.

This next chronological phase (i.e., post-1500 BC/3450 BP) has, indeed, increasingly been the focus of intensified examination in regions to the east of the core area of Qijia development. For example, the Central Plains development-from the Erlitou culture (c. 1750-1500 BC/3700-3450 BP) to subsequent stages of the Bronze Age associated with the period of the Shang Dynasty-has been a consistent focus of archaeological interest centered on studies of early state development in China (Bagley, 1999; Campbell, 2014; Fitzgerald-Huber, 1995; Liu \& Chen, 2012; Liu \& Xu, 2007; Xu, 2009), and on the emergence of a more globalized world of polities in the early first millennium BC (Shelach \& Jaffe, 2014). However, in the core regions of the Qijia culture itself, mostly within modern-day Gansu, far less is known about the 'post-Qijia' period, although a basic cultural chronology is generally accepted. Following the Qijia culture in these regions, a number of archaeological cultures sprang up during the latter part of the second and early first millennia BC (Li et al., 2010; Wang, 2012). Some cultures-including the Kayue 卡 约 (c. 1800-1500 BC/3750-3450 BP) and Siba 四坝 (c. 1950-1550 BC/3900-3500 BP) cultures in the northern parts of Gansu and Qinghai-overlap with the latter part of the Qijia date range but post-date Qijia in specific regions. Others-such as the Xindian 辛店 (c. 1600-600 BC/3550-2550 BP) and Siwa 寺 洼 (c. 1300-500 BC/3250-2450 BP) cultures in the Central and Eastern parts of Gansu Provincefollow the later Qijia materials that are in these regions (Shui, 2001). Their character and chronology are poorly understood - to date only a handful of sites, mostly cemeteries, have been excavated-yet they remain critical for understanding the broader universe of communities in the region around 3000 years ago (Jaffe \& Hein, 2020). Siwa and Xindian, in particular, are archaeological traditions associated with communities that may have engaged in new subsistence practices, such as animal herding, following a long process of climate changes.

The study of these Siwa and Xindian archaeological cultures began with their initial definition and classification by Andersson (1925) in the early twentieth century. From that point to the present, much of the archaeological work in the associated region and time period has revolved around sporadic excavation of cemetery sites and an associated close study of ceramic styles aimed at defining archaeological cultures (Li et al., 2010; Lu, 2013; Shui, 2001; Wang, 2012). Typology and classification of these ceramics is pursued as an end in itself, as occurs in other areas of Chinese archaeology (Campbell, 2014; Hein, 2016; Jaffe et al., 2018; Shelach, 2009), with the presumption that outlining the similarities and differences in ceramics provides a direct line of evidence of social relationships among different groups. Consequently, little is known about site size and layout during these pivotal times. Even less can be said of broader economic patterns or aspects of social relations not reflected in ceramic styles, although there are some proposals based on scattered 
evidence, in large part framed in relation to environmental changes and their effects on subsistence practices (e.g. Dong et al., 2013).

A common view is that the end of the Qijia culture was associated with agricultural collapse and the emergence of economies reconstructed as based on pastoral, and even nomadic, sheep and goat herding-chief among them the Siwa culture (e.g. Liu et al., 2010). Such assumptions, however, are based on cursory data and represent two principal lines of evidence that require critically examination: one is the belief that a severe $\sim 4.2 \mathrm{k} \mathrm{BP}$ climatic event documented in various places in the northern hemisphere would have forced a shift in subsistence practices (e.g. Li et al., 2015; Ma et al., 2014, 2016; and see Jaffe et al., 2020). A second is the identification of what appear to be deer-hunting motifs found painted on Xindian ceramic vessels. These have been interpreted as suggesting the prominence of such animals in the economy (e.g. Xie, 2002). These arguments, however, are based on assumptions that have not yet been substantiated by corresponding faunal, palaeobotanical, or other evidence allowing for inferences on subsistence practices during that period (Jaffe \& Hein, 2020).

A concerted focus is needed to assess this proposed transition in climate and subsistence practices, at both the regional (e.g. Yang et al., 2019a, 2019b) and local level, considering individual sites and sub-regions carefully to understand local manifestations of social and economic change during this period. Here we report on the results of such an effort focused on the Tao River valley, where the type sites of the Qijia culture (Qijiaping), Xindian culture (Xindian) and Siwa culture (Siwashan) are located. The Tao River Archaeological Project (TRAP) — a collaborative effort between Harvard University, the Gansu Provincial Institute of Archaeology, and Beijing University-is focused on investigating various aspects of technological change and the social and economic character of the Tao River valley throughout the late Neolithic and Bronze Age periods. Recent work at both the Xindian type-site and a nearby contemporaneous site called Huizuiwa affords a new window into the internal layout of Xindian period sites, as well as a finer understanding of local-specific community economic strategies in their environmental contexts (Fig. 1). Survey and excavation of domestic sites, combined with a number of analytical studies - ceramic artifacts, botanical and zooarchaeological remains and geomorphological inspections-provide, for the first time, a picture of these communities and their lifeways. We propose the combination of these methods to be a useful approach for continued work in this region. Indeed, even as the results of our work are a culmination of several years of field and laboratory work, they are still limited. Even so, they are far beyond anything done in the region to date (and see overview below). As such, they allow us to evaluate the models that dominate the current literature. We observe that Xindian sites in the Tao River valley were more compact than residential sites of earlier periods, and they seem preferentially to be positioned defensively. Furthermore, remains of animals and plants from Xindian culture contexts at Huizuiwa reflect a considerable investment in the raising of sheep and goat, but also a continued reliance on domesticated crops, with a shift toward and increased reliance on grains introduced from western Eurasia: wheat and barley. Based on comparison with data from the Qijia period in the same region, we observe that these changes occur over a relatively long period, 


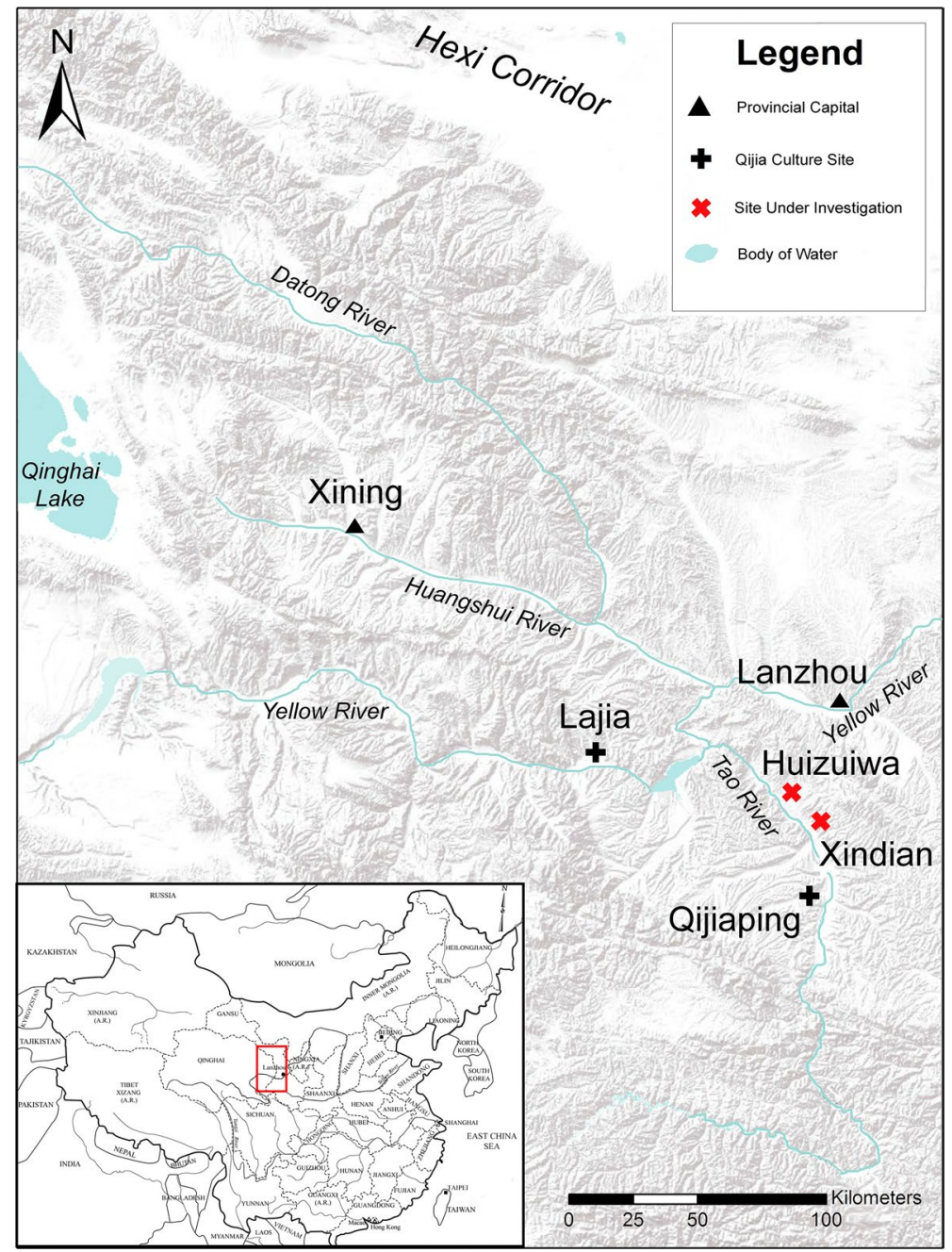

Fig. 1 Map showing key sites in the Tao River Valley (Color figure online)

indicating that claims that the post-Qijia culture phases developed as an immediate and punctuated response to the aforementioned climate changes around $4.2 \mathrm{k} \mathrm{BP}$ should be questioned in the case of the communities in the Tao River valley.

\section{The Xindian Culture}

The western regions of modern-day China, particularly around the headwaters of the Yellow River and surrounding regions, have not received the same level of scholarly focus as the lower Yellow River valley, traditionally viewed as the center of Chinese 
civilization. In fact, connections and influences between these western regions and the traditional core have shaped studies of cultural developments in both areas (Jaffe $\&$ Hein, 2020). Examples of connections and influences are purported to have been found, archaeologically, in the styles of early bronze artifacts at Erlitou (Mei et al., 2015), and in textual data on Qiang captives, possibly brought from the west, and who were scarified by the Shang in the Central Plains (Xia, 1949; Hu, 1980)—a connection proposed through stable isotope studies as well (Cheung et al., 2017). A number of scholars have viewed the upper Yellow River and adjacent areas, including the headwaters of the Wei River, as the origins of the barbarian hordes who would bring down the Western Zhou Dynasty (Zhao, 1989; Li, 2006). This is also the region in which the Qin state developed, and from which it would go on to unite 'all under heaven' and create the first Chinese empire (Pines et al., 2013).

When Swedish geologist turned archaeologist J. G. Andersson first worked in this region, China's Stone Age past was not well understood (Chang, 1986, pp. 4-5). Andersson set out to investigate a hypothesis of a western origin for China's past. His work initially led him to posit that the Yangshao Neolithic culture might have roots in migrants from Eastern Europe (Andersson, 1925). His work in Gansu was part of an effort to document potential connections between these far-flung parts of Eurasia. While ideas of direct connections across Eurasia have long been discredited and repudiated (including by Andersson himself: see Fiskesjö \& Chen, 2004), his archaeological discoveries and cultural classification have had a lasting effect, most notably in establishing an initial typology and sequence for ceramic traditions and associated cultures.

Over the past few decades, archaeological work has shown that the Neolithic trajectory of development in this western region had its own character, albeit one connected to some characteristics of traditions further to the east-mostly seen through ceramic stylistic comparisons (Li et al., 2010; Wang, 2012). The widespread but somewhat heterogeneous Yangshao archaeological culture was followed by a sequence of painted pottery cultures, which are often grouped under the term 'Majiayao culture' (which was chronologically the first of them) (see Table 1). In sequence these successive traditions are the Majiayao, Banshan and Machang. These are followed by the Qijia culture, which was quite widely distributed, encompassing parts of the Hexi Corridor and most of southeastern Gansu, and with evident connections to places as far away as the sites of Erlitou in Henan (Fitzgerald-Huber, 1995; Jaang, 2011; Mei, 2003) and Shimao in northern Shaanxi (Yan, 2010)_ although the nature of these contacts remains unclear, as they are evidenced by sporadic finds of material culture and similar stylistic decoration alone. Overlapping with and following the end of the Qijia culture, a number of cultures sprang up during the second millennium BC. Among these, was the Xindian culture (c. 1600-600 BC or c. 3550-2550 BP, see Table 1).

The Xindian culture was given its name by Andersson after the initial discovery in 1924 of a new ceramic facies at the site of Xindian, Lintao County, Gansu Province. Having discovered Xindian-type ceramics at two settlements and four grave sites in 1925, Andersson declared enthusiastically: 'the Hsin Tien (Xindian) stage is one of the best known in the whole prehistoric record of Kansu' (Andersson, 1925 , p. 15), a statement that seems ironic in hindsight, given that the other types of 
material first identified by Andersson are now much better known than Xindian-type material. Conversely, the Xindian material does not appear at all in the Zhongguo Kaoguxue 中国考古学 [Chinese Archaeology] series published by the Academy of Social Sciences (Zhongguo Shehui, 2003), but Xindian culture sites are reported in the Gansu volume of the Zhongguo Wenwu Dituji 中国文物地图集 [Atlas of Cultural Heritage in China]. What still holds true, though, is Andersson's assessment that the Xindian-type pottery differs markedly from all other ceramics in Gansu in ceramic quality as well as decorative motifs. Andersson saw this ceramic tradition as having developed from the Machang tradition, pointing to the foreshadowing of typical Xindian vessel forms in Machang assemblages (Andersson, 1943, p. 217). The date of the Xindian culture was pushed considerably later by the 1956 discovery of Zhangjiazui and Wujia, where Xindian material was found in layers above Qijia remains, showing that Xindian not only postdated Machang, but also Qijia (An, 1956).

Survey and excavation work conducted by Chinese teams since the late 1940s led to heated discussions about the nature of Xindian as an archaeological culture and its connection with other cultures, phases, or sub-groups. The Xindian culture is still believed to have derived from the Qijia culture (Nan, 1989), but after the discovery of Zhangjiazui 张家咀 and Jijiachuan 姬家川 sites in 1947, both of them yielding ceramics similar to the material found at Xindian yet having particularities of their own, scholars started distinguishing two Xindian sub-groups (Zhongguo, 1980a), adding a third with the discovery of Shanjiatou 山家头 in 1984 (Pei, 1987). The material from Tangwangchuan 唐汪川 discovered in 1956 leads to much additional controversy, with An (1956) proposing the term Tangwang-style pottery and suggesting the existence of a separate Tangwang culture.

At present, the controversy around the internal division of the Xindian material continues as different scholars distinguish different subtypes (An, 1999; Yan, 1978; Ren, 2016). A common approach is to distinguish between ceramic assemblage styles found in Zhangjiazui, Jijiachuan and Shanjiatou types. Xie (2002) finds that the Shanjiatou type, which is found in Minghe county, Qinghai along the upper regions of the Yellow river, along the Tao river, and along the Xia river, is succeeded by the Zhangjiazui type as its second phase. In contrast, the Jijiachuan type is reported as more widespread and found along the upper reaches of the Yellow river valley, along the Xia and Tao rivers and additionally as far east as the upper reaches of the Wei river and Baoji county in Shaanxi. Shui (2001) agrees with this assessment, though he finds the Jijiachuan to be an earlier variant of Xindian culture. The details of these subtypes and the related typological debates center on the forms and decorations on Xindian-style ceramics.

So far, the few existing summary publications on Xindian have focused on issues of typology based on ceramic forms and decoration, providing little information on issues of technology and describing even the occurrence of specific ceramic forms or decorations with vague terms such as 'common', 'some', or 'few' rather than absolute numbers or percentages (e.g. Ren, 2019; Xie, 1985). This is because the majority of Xindian sites were either excavated early (i.e. in the 1930s to 1950s), and the resultant reports thus do not conform to modern expectations of precise reporting, or have only been surveyed or subjected to test excavations, resulting in 


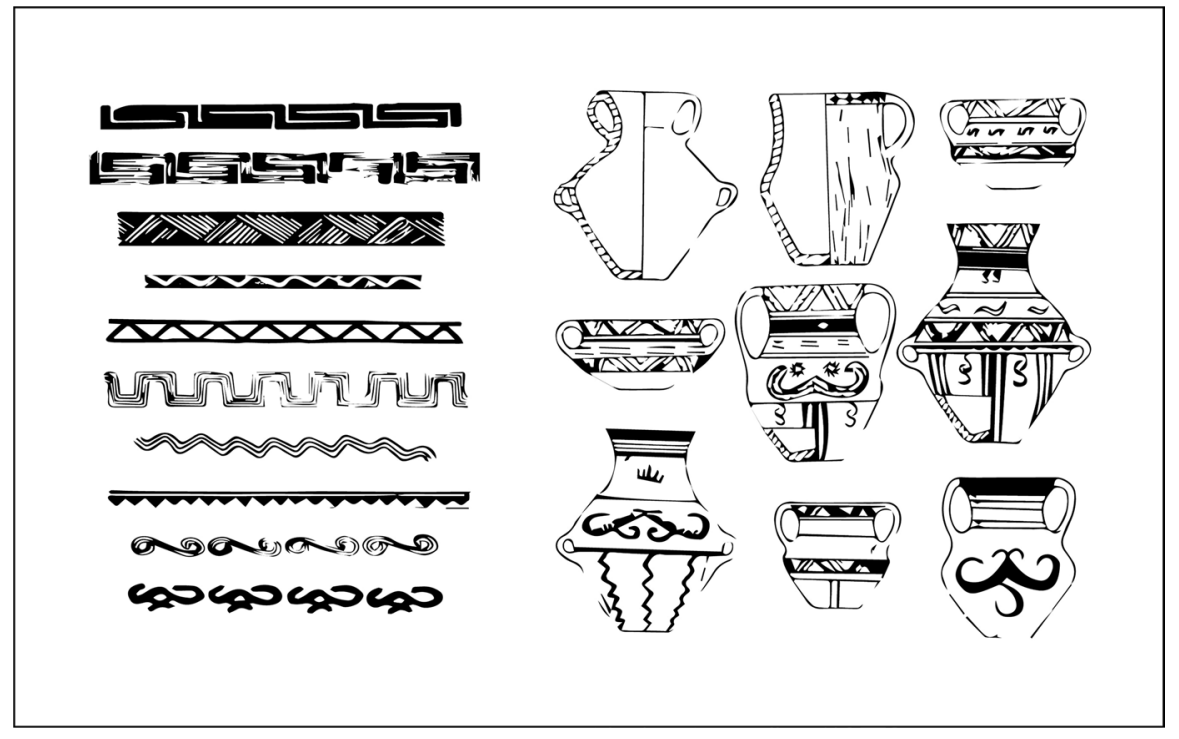

Fig. 2 Common Xindian vessel types and painted decoration styles, redrawn after: right (Zhongguo, 1980a, p. 211), and left (Qinghai, 1995, p. 4)

preliminary reports that did not have enough data for the authors to feel comfortable providing absolute numbers. Since even the more recent site reports are vague in their terminology, the description here also has to remain a little vague. The ceramic forms usually associated with Xindian comprise double-handled jars of various proportions, single-handled cups, small-eared jars, vases, stemmed cups, bowls, and three-legged $l i$ vessels, the latter marked with corded ware impressions. Other vessel types are often decorated with black (or, more rarely, black-and-red) geometric, zoomorphic or anthropomorphic designs, in some cases applied on thick white or red slip over often very coarse reddish-brown bodies. Painted motifs are quite striking and include triangles, net patterns, interlocking T-shaped patterns, thin hook shapes, and meandering bands. Sometimes the rims are decorated with fingertip-impressed appliqué strips. In what is deemed to be the latter part of this period, vessels with decorative bands executed in black or black-brown paint covering larger parts of high-shouldered double-handled jars begin to appear (Xie, 2002). The black or black-brown paint is often applied over corded ware and/or purple, white, orange, or red slip. The patterns are often arranged in decorative bands, mostly horizontal ones on the upper part of the vessel, but sometimes joined by vertical ones on the lower part. Additionally, some vessels carry stick-figure-like paintings of birds, dogs, sheep/goat, other four-legged animals, people, and sun symbols, usually arranged in between the 'mustaches' (double hooks/horns) or other broad-stroked decorations (Fig. 2).

It is important to note that thus far, Xindian culture excavations have only been conducted at 11 sites in Gansu and four sites in Qinghai Province. In Gansu these are: Xindian 辛店, Huizui(wa) 灰嘴山, and Sishiding 四十定 (all excavated by 
Andersson in the 1920s); Zhangjiazui 张家咀 (Zhongguo, 1980a); Jijiachuan 姬 家川 (Zhongguo, 1980a); Lianhuatai 莲花台 (Zhongguo, 1980b; Gansusheng \& Beijing, 1988); Yatou 崖头 (Gansusheng, 1981); Maluyuan 马路塬 (Zhang \& Pu, 1985); Yanchang 盐场 (unpublished; mentioned in Shui, 2001, p. 205); Heitouzui 黑头咀 (Huanghe, 1959); and Shizhaocun 师赵村 (Zhongguo, 1999). In Qinghai they are: Hetaozhuang Xiaohandi 核桃小旱地 (Qinghaisheng, 1995); Liuwan 柳 灣 (Qinghaisheng \& Zhongguo, 1984); Huzhu Zongzhai 互助总寨 (Qinghaisheng, 1986); and Bojizhang 䈐箕掌 (Gao \& Wu, 1984).

Few residential remains have been unearthed and only two known structures have been documented. The best preserved is from Jijiachuan (F2): a semi-subterranean rectangular pit, roughly $5 \times 3 \mathrm{~m}$ in area, which included a ramped doorway facing east. The floor contained a layer of hard soil composed of a mixture of lime and earth and its center contained a small hearth. Remains of postholes and decayed wood led the excavators to reconstruct a structure made of wooden frame and walls mixed with earth and grass (Zhongguo, 1980a, pp. 205-206). In contrast, hundreds of pits have been found in Xindian residential zones. For example, at Lianhuatai 莲 花台, over 200 pits were excavated containing a wide range of artifacts including ceramics vessels, stone and bone tools, and a circular pit where a male and female were buried side by side (Zhongguo, 1980b, pp. 297-298).

The majority of archaeological work has focused on the excavation of graves and cemeteries and the documentation of evolving burial customs. Xiaohandi 小旱地 is one of the largest excavated Xindian cemeteries with 367 graves (Qinghaisheng, 1995). The burials are mostly simple rectangular pits oriented northeast and southwest. Altogether 93 graves have been reported as having some internal furnishings, mostly wooden coffins. On a few occasions (the report does not specify how many) a two-layered coffin is interred, nearly always associated with a stepped ledge (ercengtai 二层台). The dead were placed in a supine position, with hands placed on the abdomen and the head facing to the right or left of the body. The majority of interments (277) were secondary burials, and 82 were primary burials; 358 were individual burials, but there was also one double burial and 8 cenotaphs. Where skeleton positions could be made out, supine burials were the most common (78) but in most cases the exact position was unclear. All but 16 graves contained burial goods, typically ceramic vessels. The most common ceramic type is the double-handled guan jar, along with basins (pen), vats (weng), and $h u$ pots. The Xiaohandi cemetery contains a high number of painted pottery vessels: over $90 \%$ of the assemblage contained painted decorative elements, mostly comprising geometric patterns or the famous deer antlers/moustache motifs (Qinghaisheng, 1995, p. 5, and see Fig. 3). Some burials also contain stone and bone tools as well as animal bones but this is unusual; more common is the inclusion of items for body decoration. Such ornaments are often the most abundant artifact type placed in a grave. One particularly rich grave contained more than 600 stone beads, as well as dozens of bone and metal pao ornaments - small metal objects that may have been bosses added to clothing or other materials (Qinghaisheng, 1995, p. 10).

In addition to the shaft-pit burial form, other burials containing Xindian-style materials include intricate multi-chamber catacomb tombs (Xie, 1985). Ma (2013) has argued that this tradition was most commonly produced during the early second 


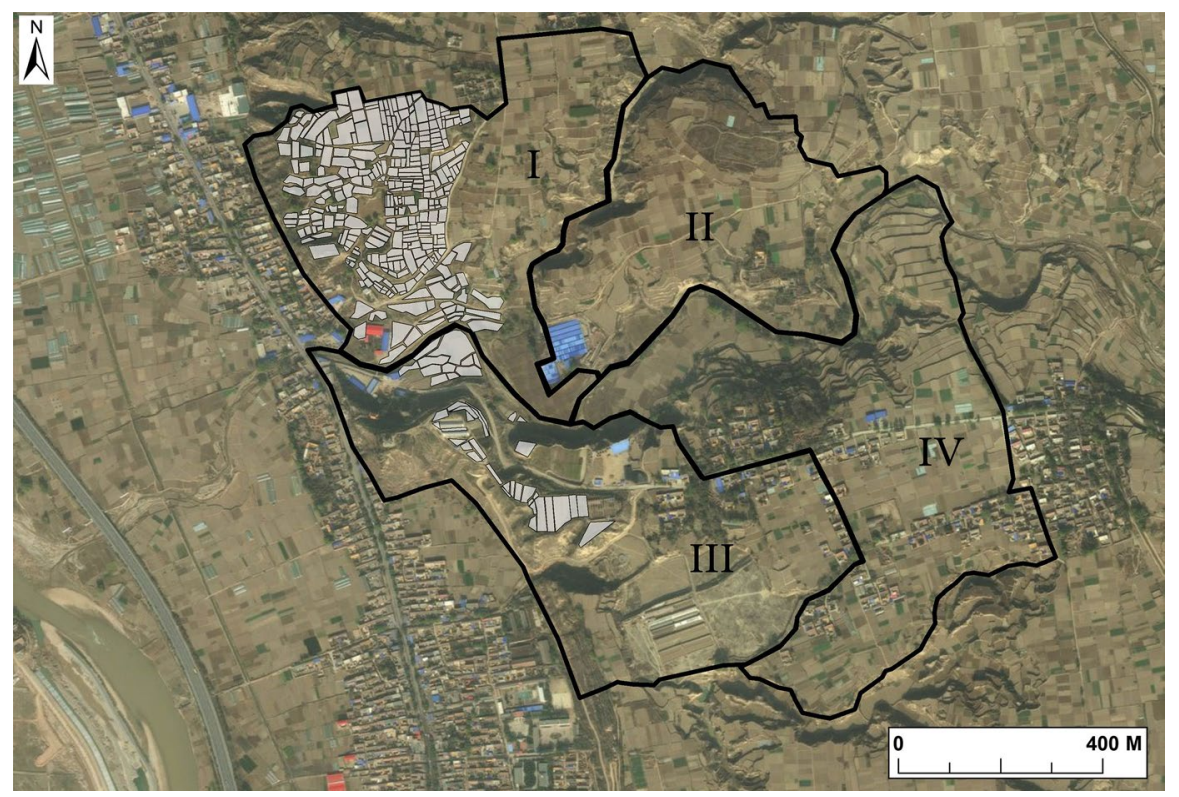

Fig. 3 Map of the Xindian site with survey areas and collection units. Note Zone I overlaps with Anderssons's Xindian A, and Zone III mostly with Xindian B (although the northernmost collection areas in Zone III are associated with Xindian A) (Color figure online)

millennium BC (the Late Qijia culture, Early Siba culture, and Early Kayue culture), but was preserved, to some extent, during the Xindian period. Ultimately, Ma argues, the practice may have been transmitted to members of the Zhou ethnic group from people to the west. Sporadic evidence of such contact can be seen in the form of Xindian vessels found in Baoji (Lu, 1985), though its intensity and character remain unclear. A third burial form appearing at Xindian sites consists of secondary burials containing multiple disarticulated individuals (some missing their skull), such as those found in pits at Lianhuatai (Gansusheng \& Beijing, 1988) and Yatou 崖头 (Gansusheng, 1981). Cheng (2006) contends that what was first considered to be the result of poor preservation and later disturbance was actually an intentional interment rite. In fact, this practice is so prevalent that Chen argues it should be considered the main burial custom for the Qinghai and Northern Gansu region. Indeed, the site of Lajia 喇家 contained a number of post-Qijia graves where secondary burials and multiple burials where found in oval-shaped graves (Minhe, 2015), though some have questioned their identification as Xindian culture (Ren, 2017).

This overview of the Xindian-with the vast majority of the data derived from mortuary contexts-provides a near-exhaustive account of this archaeological culture. By itself it illustrates a concern with identifying chronology and, to some extent, shared cultural practices that imply some sort of shared identity. This sort of summary does not, however, provide insights into economic or social practices. We now turn to discussing how Xindian people and economy have been presented, 
paying special attention to the impact a changing environment is believed to have had on previous subsistence lifeways.

\section{Second Millennium BC Northwest China: Climate Change and Economic Consequences}

The basic background of the geographical extent, chronological range, and homogeneity (or heterogeneity) of Xindian materials and associated practices in previous research lacks discussion of community forms or subsistence practices, except for the aforementioned assumptions concerning a transition toward pastoralism. It has been assumed that the groups creating and using Xindian-style ceramics relied on cereal agriculture, though caprine husbandry is also believed to have gained increased importance over time (e.g., An et al., 2005; Liu \& Feng, 2012; Shui, 1989; Wu \& Liu, 2004; Xie, 2002, p. 179; Xu, 1988; Yang et al., 2019a, 2019b). The basis for the reliance on cereal agriculture and caprines is the combination of a considerable number of agricultural tools at Lianhuatai, Jijiachuan, Zhuangjiazui and similar sites, along with limited zooarchaeological evidence of domesticated sheep and goat. At Zhangjiazui the excavators note a large number of bone and stone tools at the site suited for a wide range of agricultural practices (Zhongguo, 1980a, pp. 216-217). Some stone and bone tools have long and thin blades suitable for tilling the earth, and the site contains many mortars and pestles, possibly for processing grains (Zhongguo, 1980a, p. 215). Previous archaeobotanical analyses from sites in the Guangting Basin, Qinghai (preliminarily assigned to the Xindian culture) have shown the presence of broomcorn and foxtail millet, barley, wheat, hemp, and other plants (Zhang, 2012, p. 28). Whereas Qijia sites in the same region contained a larger proportion of foxtail millet, the remains purported to be related to Xindian materials contain more broomcorn millet, and the investigator interprets this as a switch brought on by the onset of drier conditions (Zhang, 2012, p.30).

The combination of a seed density much lower than at Qijia sites, and large amounts of animal bones, especially sheep/goat (Zhang, 2012, p. 31; Zhongguo, 1980a, p. 210), has led some scholars to argue for a decline in intensity of cereal agriculture and a shift toward a mixed subsistence economy (e.g. Hou et al., 2009). The finding of hooks and nets further suggests inhabitants may have supplemented their diet with deer and fish (Zhongguo, 1980a, p. 220). Indeed, Xindian sites so far have yielded sheep/goat, pig, cattle, dog, and sometimes horse bones, as well as deer. Recent isotopic analysis of two herbivore bones from Wenjia showing a $\mathrm{C}_{4}$ signature suggests that domesticated animals, possibly sheep/goat or bovids, may have been fed agricultural crops, given that this signature would reflect millet consumption but does not correspond to the background $\mathrm{C}_{3}$ plants that are common in the region (Ma et al., 2016, p. 26; see also Barton et al., 2009, p. 5524). This would not be a surprising result given the practice of foddering domesticated animals with millet, shown isotopically elsewhere in the North China Neolithic (Barton et al., 2009; Chen et al., 2015; Dai et al., 2016a, 2016b), but the small sample size demands caution. At present, these can only be preliminary suggestions. 
Changes or continuities in subsistence between the Qijia and Xindian communities should be considered in relationship to broader environmental trends during the second millennium BC. The past decade has seen a rise in deterministic models focusing on climate change. One example, variously termed the ' $\sim 4.2 \mathrm{k} \mathrm{BP}$ event' (a term borrowed from the Near East), the 'c. 4000 cal yr BP climatic event', and the 'Holocene event 3' is understood to represent a phase of global environmental stress (at least in the northern hemisphere), which had wide-scale social, political and economic implications as its effects were differentially felt over centuries (e.g. Booth et al., 2005; Dalfes et al., 1997; deMenocal, 2001; Hsu \& Perry, 2002; Meller et al., 2015). In the region of concern in this article, some scholars have associated this period of climate stress with cultural change, including employing the event to explain the transition from Qijia (c. 2200-1500 BC/4150-3450 BP) to subsequent cultures. In such discussions, Xindian (c. 1600-600 BC/3550-2550 BP), along with Kayue (c. 1800-1500 BC/3750-3450 BP), Siba (c. 1950-1550 BC/3900-3500 BP) and Siwa (c. 1300-500 BC/3250-2450 BP) are seen as communities practicing pastoral nomadism. This line of argument proposes that in regions of northern China including Inner Mongolia, Qinghai and Gansu, a prolonged period of aridity and cooler temperatures eventually resulted in the collapse of many existing societies, as well as a transition from cereal agriculture to pastoral or agro-pastoral communities (e.g. An et al., 2005; Liu \& Feng, 2012; Wu \& Liu, 2004).

Although called an 'event,' the $4.2 \mathrm{k} \mathrm{BP}$ variation is in reality a multi-centennial scale transition to cooler and drier conditions that have been noted in several proxies (see e.g.: Dykoski et al., 2005; Hou et al., 2016; Kaufmann et al., 2020; Liang et al., 2020; Marcott et al., 2013; Wang et al., 2005; Zhao et al., 2009). The onset of cooler and drier conditions is at roughly $4200 \mathrm{cal} \mathrm{BP}$ and is followed by a continued decline in both temperature and precipitation - though recent work has highlighted subsequent multi-decadal oscillations, as well as regional-specific spatiotemporal variations (e.g. Cai et al., 2017; Railsback et al., 2018; Tan et al., 2018; Zhang et al., 2018a, 2018b). Multi-proxy modelling by d'Alpoim Guedes and Bocinsky (2018) suggests that these reach their lowest point at $3600 \mathrm{BP}$, after which temperatures increase slightly, but never again reach the high levels of the earlier Holocene climatic optimum. Although on a geological scale this process is rather short, in relation to cultural change, the hundreds of years over which changes occur and would have been perceived by people is quite significant. Recognizing the multi-centennial scale of this transition calls into question some of the arguments for abrupt cultural changes directly tied to this event in some of the literature (e.g. Liu \& Feng, 2012; Wu \& Liu, 2004).

Another aspect of the problem is the confusion in the literature over the timing of the beginning and end of the Qijia culture (see overview in Jaffe \& Flad, 2018). Most existing data on the cultural chronology would place the beginning of the Qijia period roughly around the same time as the onset of this climatic event (i.e., around 4200 BP). It is noteworthy that the Qijia phenomenon did not suddenly appear across the entire region where we ultimately find Qijia remains. Instead, earlier Qijia sites are found in the more eastern parts of the overall distribution, while later in the sequence, areas like the Tao river are occupied. The overall chronological range for the Qijia culture, which we list as c. 2200-1500 BC/4150-3450 BP, much less the 
entire distribution range of the Qijia culture, cannot necessarily be ascribed in its entirety to any one region.

When the so-called collapse of the Qijia culture has been most explicitly attributed to the events of $\sim 4000$ cal. yr BP and the replacement of dry farming with pastoral subsistence practices by the cultures that followed it (Mo et al., 1996; Shui, 2001) scholars seem to be engaging in one of two processes. They are either modifying cultural chronologies to fit assumptions about the effects of environmental change or they are accepting uncritically the chronological scope of an archaeological culture to apply uniformly across the region where associated sites are found (and see Jaffe et al., 2020). In the case of some scholarship that has associated the collapse of Qijia and the onset of Xindian and other cultures with the $4.2 \mathrm{k} \mathrm{BP}$ event, we consequently see an adoption of a short chronology for the Qijia culture. For example, for An et al. (2005), the Qijia culture is dated to 4300-3900 cal BP, and they propose that while the associated society flourishes early on, marked by the development of sophisticated technologies and larger site numbers and regional distribution, it collapses quickly after the $\sim 4000$ cal. yr BP event (note that here the event is referenced as c. $4000 \mathrm{cal}$ yr BP, rather than $4.2 \mathrm{k} \mathrm{BP}$ ). Liu and Feng (2012), in contrast, place the Qijia dates at 4000-3800 cal. yr BP, yet similarly find that the Qijia culture flourishes during its initial phases but soon declines due to the continued effects of this climatic event. In this narrative, the Qijia are succeeded, after an additional hiatus of 200 years, by a number of different cultures, each occupying its respective zone more sparsely and exhibiting cultural atavism or the reversal of the advances of the preceding culture.

Conversely, Liu et al. (2010) extend the duration of the Qijia culture from 4000 to $3600 \mathrm{BP}$ and note the more severe climatic influences (extremely low temperatures), which characterized the period from 3.9-3.6 k BP. In this argument the prolonged effects of the climatic event slowly chipped away at Qijia society until it collapsed around $3600 \mathrm{BP}$, resulting in a separation of nomadism from farming. The turn to an increased emphasis on pastoral economic practices was followed, they believe, by most subsequent societies, but to varying degrees based on the environmental zone of those cultures that succeeded it: from pastoral nomadism of the Kayue in Qinghai, to a mixed agro-pastoral economy of the Siwa culture in the higher altitudes of Southwest Gansu, and the survival of farming in the Xindian culture occupying the moderately warmer climate of the Yellow River valley.

As noted above, the available archaeological evidence for the Qijia and subsequent periods remains scarce, rendering testing the above models problematic. Furthermore, the archaeological data currently available is mostly from graves and can thus provide limited insight into supposed subsistence changes (Jaffe \& Hein, 2020). Only a handful of sites have been excavated sufficiently to show catastrophic events - the exception being the site of Lajia in Qinghai Province, where the Qijia period levels were destroyed by a cataclysmic flash flood and/or earthquakes, burying inhabitants alive at c. 3950 cal. BP (Zhang et al., 2018a, 2018b). This catastrophic event may have impacted a number of communities along the Yellow River (Huang et al., 2013; Wu et al., 2016; c.f. Wu et al., 2017), however, it does not necessarily reflect a regional climatic shift that would have had widespread impacts on the economic and social practices of Qijia communities more generally. Moreover, 
others argue that the lake proposed to be responsible for the dam-burst flood had already disappeared by c. 3600 BC (i.e., c. 5600 cal. BP, more than 1600 years earlier), and that other skeletal remains from the site date to the period between 1875 and 1662 cal BC (i.e., 3825-3612 cal BP; Dong et al., 2018). Accordingly, flooding may have occurred less catastrophically, but perhaps frequently, over a drawn-out period of several hundred years.

The dates at Lajia also demonstrate Qijia cultural dates in the western part of the Qijia distribution closer to $1600 \mathrm{cal}$. BC (3550 cal. BP). Our work at the site of Qijiaping 齐家坪, roughly $250 \mathrm{~km}$ southeast of Lajia, has uncovered Qijia-culture occupation that ranges between 1631 and $1431 \mathrm{cal}$. BC (3581-3381 cal. BP) based on 12 dates from two pits (Brunson et al., 2020; Womack et al., 2021). The data from Qijiaping imply a flourishing of Qijia culture in the Tao river region in a 150year period, and combined with other Qijia culture contexts in the Tao River valley, such as the site of Mogou (Gansu \& Xibei, 2009), these data show an intensity of occupation in the Tao river valley at the time when others have suggested that Qijia is collapsing, possibly because people may have migrated there from other regions. Even recognizing that the climate changes that began at $4200 \mathrm{BP}$ took a long time to impact communities in different areas, in the Tao river valley the impacts may have been very different from elsewhere.

Indeed, given the multi-centennial nature of climate change human societies do not demonstrate uniform, clear-cut strategies in response to specific climatic events (Haldon et al., 2018; Izdebski et al., 2016; Jaffe et al., 2019; Meltzer, 2015). In Northeastern China, the onset of the 4000 cal. yr BP event was followed by a distinct flourishing of society during the Lower Xiajidian 夏家店下层 period (c. 2200-1600 BC/4150-3550 BP), when the region was densely populated by large and stable communities practicing subsistence agriculture (Chifeng, 2011; Shelach, 2009). Might a similar florescence have occurred during the later part of the Qijia or even post-Qijia instead of the full scale transition to pastoralism that has been proposed? Careful study combining improved models (d'Alpoim Guedes et al., 2016a, 2016b; Goldsmith et al., 2017) of site-specific (Zhuang \& Kidder, 2014), region-specific (Su \& Kidder, 2019), and historical data (Haldon et al., 2018; Pederson et al., 2014) are needed for an accurate understanding of human-environment dynamics (McAnany \& Yoffee, 2009; Redman, 2005; Tainter, 2006). As a first step, we need to start with a basic understanding of the local chronology and the regionspecific sequential cultural and economic manifestations.

What we can say with the evidence at hand is that the Qijia culture flourished during its later phases in the western portions of the broader Qijia cultural range, including in the lower Tao River valley, until as late as c. $1431 \mathrm{cal}$. BP/3381 cal. BP. Following the occupation of Qijia culture sites in this valley, including the culture type-site of Qijiaping (Womack et al., 2017, 2021), the area is occupied by communities creating ceramics of the Xindian cultural tradition. The distribution of Xindian sites displays a relatively clear geographical pattern in the Tao River valley. Xindian sites are found in the northern, lower reaches of the river valley between 1700 and 2100 masl. Further south, sites that post-date the Qijia culture are associated with the Siwa tradition, mostly distributed at elevations of 2000-2700 masl, generally higher than Xindian sites (and see Womack et al., 2021). 
We must be cautious not to overemphasize the above trend/elevation association, as it is obtained from sites found in unsystematic surveys over the past few decades (and see Jaffe et al., 2020). Yet based on these distributions, we might expect that in addition to having different ceramic styles, the communities associated with Siwa and Xindian materials may have had different economic foci. Likewise, the differences between Qijia and Xindian cultural traditions, which are based primarily on shared practices in ceramic production and, to a lesser extent, mortuary practices, may also reflect chronological changes in settlement organization and subsistence practices. In order to assess this possibility, however, baseline data is required concerning the organization of Xindian settlements and the nature of subsistence practices at these sites. Two known Xindian culture sites have been examined by the TRAP project to help develop this baseline: Xindian and Huizuiwa.

\section{Xindian}

\section{Previous Work at the Xindian Type Site}

The Xindian site is located in Lintao County, Gansu, on the eastern banks of the Tao river. Andersson's aforementioned work in 1924 initially distinguished between two parts of the Xindian site: A and B, located on opposite sides of a tributary to the Tao river. Area A was identified as a burial site of about $150 \times 150 \mathrm{~m}$ (according to Andersson's estimate) on the northern side of the ravine, while area B was identified as a settlement site. Additionally, Areas C, D \& E were also mentioned as exhibiting small accumulations of Xindian features. Andersson (1943) observed over 100 graves at Xindian A, many of which had been looted, and he proceeded to excavate 25. Ceramics similar to those he found at Xindian A also came to light in a grave he excavated $100 \mathrm{~m}$ north of Zhangjiapu, east of Xindian village (listed by Andersson as Xindian E) and in another 20 graves at Sishiding. The Sishiding graves held single primary extended supine burials with 1-3 ceramic vessels and a few bronze and bone objects; there were remains of ochre in some of the graves (Skeletons 10 and 13). Particularly revealing were small finds from Xindian A and Sishiding that included two small bronze fragments, an early metal discovery in the region.

Andersson believed that most, if not all, of the Xindian-style vessels that he had purchased in Lanzhou had come from the looted graves at this site, and thus he evaluated the purchased vessels together with the items that he and his team excavated from 25 graves at Xindian A (Andersson, 1943). The graves he excavated were earth-pit graves containing single extended supine burials accompanied by a small number of ceramics, bone and bronze tools and decorative objects, as well as in some cases stone and turquoise beads (Xindian E, Sishiding, and Skeleton 6 at Xindian A). The ceramics excavated from these graves were double-handled high-necked jars and closed bowls with or without handles, most of them painted in black or black-and-red patterns on white slip over thick reddish-brown coarse vessel bodies.

At Xindian B, the settlement sector located on a flat hilltop overlooking the river, Andersson excavated a $5 \times 2 \mathrm{~m}$ unit near the southern end of the hill, revealing refuse 
deposits of $100 \times 55 \mathrm{~cm}$. Sterile soil was reached at a depth of $1.33 \mathrm{~m}$. Andersson's excavations at Xindian B identified layers with Yangshao material superimposed by small amounts of Xindian-type material (Andersson, 1943, pp.173-175). He distinguished three layers containing stone and bone artefacts, as well as painted and unpainted pottery, most of it of Yangshao type with only very few Xindian-type fragments in the uppermost layer and on the surface (Andersson, 1943, pp.173-175; Sommarström, 1956, p. 61). From this excavation it appears that Xindian B was mostly not a Xindian settlement. Indeed, the collections of material retrieved from Xindian B held at the Museum of Far Eastern Antiquities in Stockholm consist mainly - though not exclusively — of Majiayao-style painted fine ware and some undecorated fine and coarse ware, while the ceramics from the graves at Xindian A and $\mathrm{E}$ are exclusively Xindian-style ceramics.

\section{Survey of Site and Surrounding Area}

In 1981, the Xindian site was designated a protected site at the provincial level; this was extended to the national level in 2010. The sign declaring it a protected site was placed on the northern side, that is, Xindian A, and since the southern part is referred to as Luotuoya 骆驼崖rather than Xindian B, that area has not received corresponding protection. Instead, control over this land was obtained by a company which fenced it in, whereas Xindian A remains agricultural fields that can be accessed and has consequently (and ironically) seen much looting over recent decades. According to the documents on the protected area of the site, Xindian A is a cemetery extending over $350 \mathrm{~m}$ from east to west and $813 \mathrm{~m}$ from north to south, covering an area of $284,440 \mathrm{~m}^{2}$ (i.e., $28.4+$ ha). The southern portion (Xindian B) is listed as being $13,020 \mathrm{~m}^{2}$ (186 m east to west, $70 \mathrm{~m}$ north to south).

In May 2017, we conducted a full-coverage surface survey at Xindian A and B. The area around the site was first split into four survey areas (I-IV). After extensive field walking in all four zones with individuals in teams of 3-4 walking along most field rows to identify any evidence of surface ceramics, collection areas were created in Zones I and III, roughly corresponding with Xindian A and B. In these collection areas, field walkers were at much closer intervals, with approximately 2-4 m between surveyors. A total of 366 collection areas covering an area of approximately 17 ha were investigated (Fig. 3) following the method previously applied at Qijiaping (described in more detail in Womack et al., 2017). In the collection areas in Zone I (Xindian A), the majority of collection units did not furnish any finds even in locations with limited ground cover and good visibility, leading to the collection of only 67 ceramic sherds and 1 ceramic spindle whorl from 26 out of 334 collection units, with typically only 1-3 items per unit. Xindian B collections included 240 sherds from 32 collection units, in addition to a couple of other artifacts. Only two stone objects were found during surface survey, a stone grinding rod and a fragment of a stone bracelet. One area of Xindian B contains ash pits and cultural layers of approximately $0.3 \mathrm{~m}$ thickness, visible about $0.5-2 \mathrm{~m}$ below the surface in a terrace cut along the side of a modern road.

The description of the material obtained during our survey and excavation work at Xindian and Huizuiwa provided below is the first systematic report that suggests 
both relative and absolute abundance of specific wares. The assignation of Majiayao, Qijia, Xindian, and Han was mostly based on decoration type. This initial assessment was then re-evaluated based on a combination of decoration and other surface treatments, ceramic color, paste, and where applicable vessel part/form (see Supplemental Files, available online), however, it was not always possible to be certain, and 77 of the sherds were thus labeled as 'unclear' in date and style (see Supplemental Files, Appendix I). This was mostly because many of the fragments collected during the surface survey were too small for reliable typological identification, because the area has been used for agriculture for centuries if not longer, and the constant churning of the soil has left ceramics in a highly fragmented state. Where identification was possible the majority of ceramic sherds collected from Xindian A were of Xindian or Han period (Table 2). In Xindian B, where 240 ceramic sherds, one stone grinding rod and a fragment of a stone bracelet were found, Majiayao ceramics make up the highest percentage of finds, followed closely by Xindian material and, surprisingly, a number of Qijia-type sherds.

Given the highly fragmented nature of the material, no vessel forms could be identified. The fragment forms suggest, though, that there were some flat-bottomed and handled vessels (7 handle fragments and 14 flat base fragments were found). In terms of paste types, fine ware, fine sandy ware, medium sandy ware and ware with coarse inclusions could be identified. There are significant differences between Xindian A and B in terms of relative abundance of these different ware types. For example, Xindian A has a lower proportion of coarse ware than Xindian B, however, most of the fine ware at Xindian A clearly dates to the Han or later periods. If these pieces are disregarded, the percentage of coarse wares is still low, but considering the small number of overall finds, it is difficult to draw firm conclusions (Table 3 ). The collection results from Xindian B provide considerably more robust numbers, and here the percentages of fine, medium fine, and coarse ware are more similar. It is notable that the fine wares are predominantly painted Majiayao wares, while coarse wares are often Xindian and more rarely Majiayao or Qijia-type wares (Table 2).

In terms of decoration, not counting Han period or later finds, over $40 \%$ of the Xindian A finds and over $25 \%$ of the Xindian B finds were undecorated. Common types of surface alteration at both sites include paint (mostly black, more rarely brown or red), cordmarks, and slip. Less common are appliqué, various types of impressions, or clearly discernible polishing. Slip appears mostly on Xindian wares and often in combination with paint, sometimes also with cord marks on the lower

Table 2 Ceramic finds from Xindian A and B by cultural assignation excluding modern and unidentifiable items

\begin{tabular}{lcccccc}
\hline & Xindian A & Percentage (\%) & Xindian B & Percentage (\%) & Xindian All & Percentage (\%) \\
\hline Majiayao & 1 & 2.1 & 84 & 47.2 & 85 & 37.8 \\
Qijia & 0 & 0.0 & 24 & 13.5 & 24 & 10.7 \\
Xindian & 22 & 46.8 & 70 & 39.3 & 92 & 40.9 \\
Han & 24 & 51.1 & 0 & 0.0 & 24 & 10.7 \\
Sum & 47 & 100.0 & 178 & 100.0 & 225 & 100.0 \\
\hline
\end{tabular}


Table 3 Paste type by time period disregarding Han and modern finds

\begin{tabular}{|c|c|c|c|c|c|c|c|c|}
\hline & Majiayao & $\begin{array}{l}\text { Percentage } \\
\text { (5) }\end{array}$ & Qijia & $\begin{array}{l}\text { Percentage } \\
(\%)\end{array}$ & Xindian & $\begin{array}{l}\text { Percentage } \\
(\%)\end{array}$ & unclear & $\begin{array}{l}\text { Percentage } \\
(\%)\end{array}$ \\
\hline & \multicolumn{8}{|l|}{ Xindian A } \\
\hline Fine ware & 0 & 0.0 & 0 & 0.0 & 7 & 31.8 & 9 & 64.3 \\
\hline Fine sand & 1 & 100.0 & 0 & 0.0 & 13 & 59.1 & 3 & 21.4 \\
\hline $\begin{array}{l}\text { Medium } \\
\text { sand }\end{array}$ & 0 & 0.0 & 0 & 0.0 & 0 & 0.0 & 0 & 0.0 \\
\hline $\begin{array}{c}\text { Coarse } \\
\text { sand }\end{array}$ & 0 & 0.0 & 0 & 0.0 & 2 & 9.1 & 2 & 14.3 \\
\hline \multirow[t]{2}{*}{ Sum } & 1 & 100.0 & 0 & 0.0 & 22 & 100.0 & 14 & 100.0 \\
\hline & \multicolumn{8}{|c|}{ Xindian $B$} \\
\hline Fine ware & 35 & 41.7 & 6 & 25.0 & 6 & 8.6 & 13 & 21.0 \\
\hline Fine sand & 31 & 36.9 & 10 & 41.7 & 32 & 45.7 & 22 & 35.5 \\
\hline $\begin{array}{l}\text { Medium } \\
\text { sand }\end{array}$ & 4 & 4.8 & 1 & 4.2 & 6 & 8.6 & 11 & 17.7 \\
\hline $\begin{array}{r}\text { Coarse } \\
\text { sand }\end{array}$ & 14 & 16.7 & 7 & 29.2 & 26 & 37.1 & 16 & 25.8 \\
\hline Sum & 84 & 100.0 & 24 & 100.0 & 70 & 100.0 & 62 & 100.0 \\
\hline
\end{tabular}

Table 4 Decoration type counts by time period disregarding Han and modern finds

\begin{tabular}{llrrr}
\hline & Majiayao & Qijia & Xindian & unclear \\
\hline & Xindian $A$ & & & \\
Plain & 0 & 0 & 8 & 11 \\
Slipped & 1 & 0 & 9 & 1 \\
Polished & 0 & 0 & 0 & 0 \\
Painted & 1 & 0 & 8 & 0 \\
Cordmarked & 0 & 0 & 2 & 1 \\
Impressed & 0 & 0 & 0 & 1 \\
Appliqué & 0 & 0 & 0 & 0 \\
Sum & 2 & 0 & 27 & 14 \\
& Xindian $B$ & & & \\
Plain & 15 & 7 & 18 & 35 \\
Slipped & 4 & 2 & 21 & 5 \\
Polished & 13 & 1 & 1 & 0 \\
Painted & 31 & 1 & 28 & 1 \\
Cordmarked & 40 & 13 & 20 & 20 \\
Impressed & 0 & 1 & 1 & 4 \\
Appliqué & 3 & 2 & 3 & 1 \\
Sum & 106 & 27 & 92 & 66 \\
\hline
\end{tabular}

part of the vessel, as can be seen on complete vessels retrieved from burial excavations (e.g. Andersson, 1943). The appliqué bands co-occur with cordmarks or other types of impressions on items of all three periods (Majiayao, Qijia, and Xindian), 
but cordmarks as such seem to be especially common among the identifiable Majiayao wares of Xindian B (Table 4), although this may reflect some identification bias. Many of the identified decorations are seen as typical of Xindian, especially the Jijiachuan-style material (see Andersson, 1943; Xie, 1985; Ren, 2019; and Shui, 2001 for discussions of typical Xindian ceramic forms and decorations). Some of the painted wares have a finer vessel body, though, with fine sand inclusions and carrying the broad black-painted decorations that are the hallmark of Xindian pottery despite a lack of slip (for details see Supplemental Files, Appendix I).

\section{Discussion: Preliminary Understanding of the Xindian Site}

The results of our systematic survey support Andersson's initial identification of Xindian A as a burial area and Xindian B as a residential area, as the vast majority of ceramic finds were indeed at Xindian B. Additionally, this area also displayed a higher percentage of coarse ware than was found at area A (only $10 \%$ in A but $25 \%$ in B). At Zhangjiazui, one of the few excavated and published Xindian culture residential sites, the vast majority of the excavated ceramics were, in fact, coarseware (Zhongguo, 1980a, p. 196), while at Xiaohandi cemetery, over $90 \%$ of cemetery finds were painted fineware pottery (Qinghaisheng, 1995, pp. 5-6). That said, the initial inspections of the Xindian site's ceramics found that both painted and unpainted vessels were made of coarse ware, thus showing that typological assessments based on surface treatment alone are not sufficient to understand variation in ceramic wares. Furthermore, sherds collected in surface surveys and even in settlement excavations tend to be rather fragmented, often making it difficult to reconstitute or suggest vessel forms. It can therefore be helpful to also take into account technological details such as paste types when categorizing and comparing ceramic sherds.

By calculating the density of sherds per $\mathrm{m}^{2}$ found in each survey collection unit, a map showing ceramic densities across the site was created in ArcGIS. The density map creates a continuous spatial unit for the overall spread of ceramic finds. Based on those areas where a higher density of sherds was found, a model can be generated highlighting the relationship between the different parts of the site as well as expectations for its wider spread (Fig. 4). A clear separation can be seen between the hypothesized cemetery area at Xindian A and the residential zone at Xindian B, expanding to the east and west of Xindian B.

Accordingly, we surmise that Xindian B was probably a small, dense area of settlement on a bluff overlooking the Tao river and a small drainage. There is evidence of both Majiayao and Xindian occupation in this location, and perhaps Qijia period activity as well, although the latter is more equivocal. During the Xindian period, a dedicated cemetery area (Xindian A) was created to the north across the drainage, physically separated from the small settlement area. Due to the very fragmentary nature of the preserved part of the site (and its being covered by modern buildings), we turned our attention to Huizuiwa, another contemporary site in the Tao River valley, to collect data that can speak to economic activities beyond ceramic technology. 


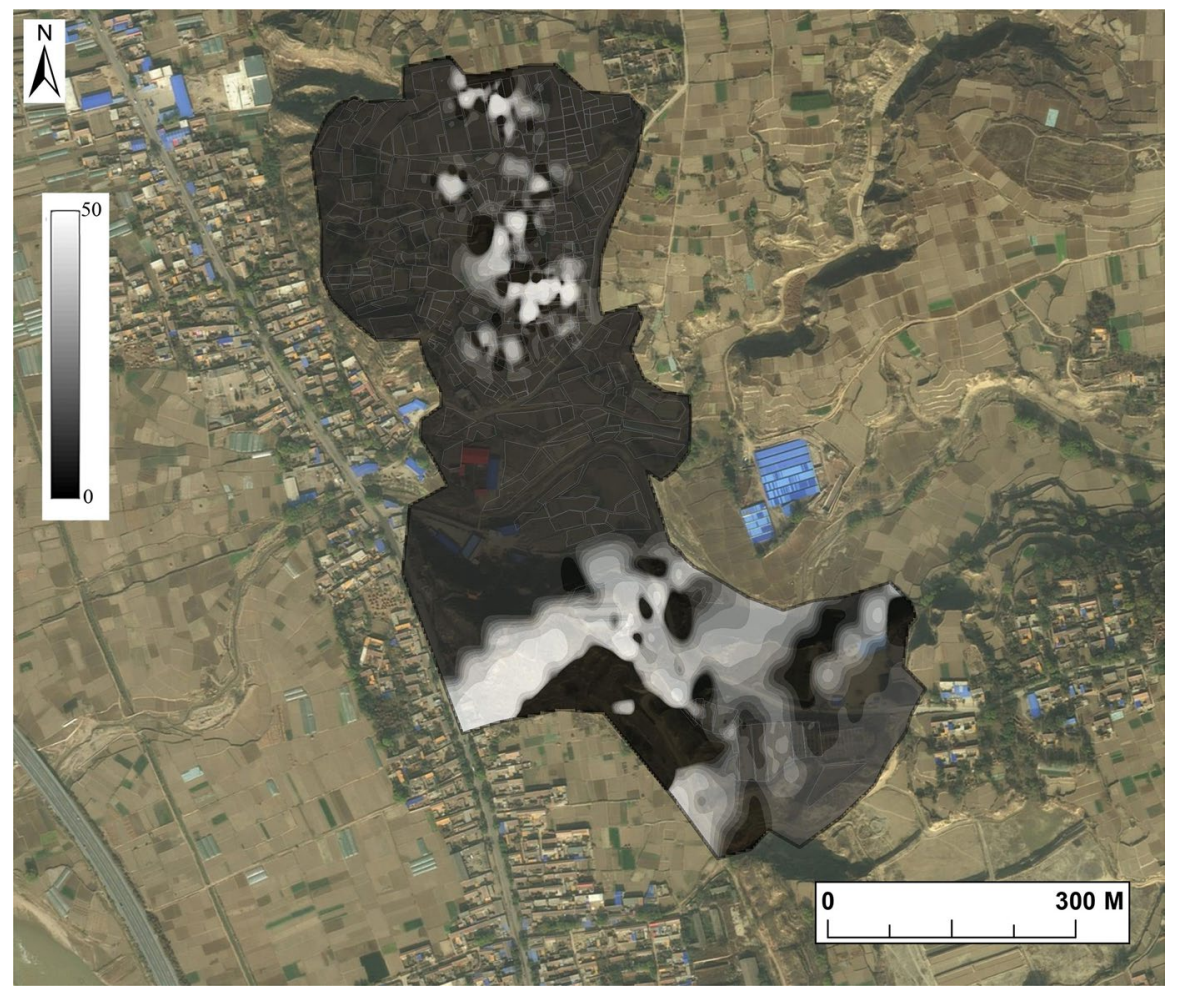

Fig. 4 Shading reflects sherd density across the Xindian site according to the scale on the left side. Numbers represent sherds per $\mathrm{m}^{2}$, with white areas reflecting the densest material (Color figure online)

\section{Huizuiwa}

\section{Previous Work at Huizuiwa}

The first visit to Huizui (now Huizuiwa) in Daosha County by Andersson furnished large amounts of Xindian-type pottery as well as coarse stone tools, animal bones, bone tools, and a small number of bronze objects (Andersson, 1943), making it a good target for work to enhance understanding of the nature of Xindian sites in the Tao River valley. The site is situated about 70-80 m above the Tao river valley on a small terrace bluff top overlooking the valley, a position quite similar to that of Xindian B. Han period and modern graves were found as well, but the disturbance of earlier cultural layers seems to have been minimalboth during Andersson's time and in the present day.

Andersson conducted a small excavation in the center of the plateau and collected ceramic material that is described as coarse, porous, thick-bodied, coilbuilt pottery (Andersson, 1943, p. 172). Vessel forms included jars, many with two short band handles; small single-handled round-bottom cups; closed bowls; urns; and $l i$ tripods. Many of the jars and some of the bowls were decorated with 
black and sometimes red paint-mostly geometric patterns including meandering wavy lines, zigzags, net patterns, and S shapes-often applied on a lightercolored slip. The body of the painted ware is red to red-brown while the grey ware is unpainted and decorated only with line incisions or impressions. The limited stone tool assemblage ( 8 items) reported by Andersson comprises axes, chisels, adzes, and various large stones of unclear function. He also reports a wide variety of bone tools such as awls, spoons, needles, combs, various other implements, altogether 23 items, and three hard-stone beads, as well as four bronze items including a curve-backed knife, a button, two nails, and one fragment of unclear original shape. A cowrie shell, and a clay figurine were also found but not further described. Additionally, he mentions large amounts of animal bones that likewise were not further analyzed or differentiated in his publications.

\section{Archaeological and Geological Survey of Site and Surrounding Area}

Although visited again by Pei Wenzhong in 1947 and listed in the survey of archaeological sites in Gansu compiled during the periodic surveys of cultural relics (most recently the Third National Survey completed in 2012), no previous systematic survey had been conducted at the site. We visited the site in 2012 to assess it for future research. During our first visit, in addition to opportunistically collecting 44 diagnostic sherds and stone tools from across the site, some of which may have come from looted tombs, we also collected a sample $1 \times 1 \mathrm{~m}$ area within which we recovered six Xindian culture sherds, reflecting a high density of sherds across the bluff top. The bluff top is also very flat and uncultivated, making the location conducive to additional survey and geophysical analysis. During subsequent work at the site we collected surface materials using two separate collection strategies: 'dog-leash collection units' and 'field-area collection units' (Fig. 5). The dog-leash collection units were located at systematically aligned grid points $20 \mathrm{~m}$ apart from each other across the area with dense ceramic remains. We collected a $10 \mathrm{~m}^{2}$ circle at each location determined by stretching a cord ('dog-leash') from a central point. In total, across the dense area of the site we collected 318 artifacts at 33 dog-leash locations, typically recovering between 10 and 25 objects per collection. Beyond the bluff top, where surface sherds were rare, we used 'field-area collections' as previously described for our work at Qijiaping (Womack et al., 2017), and the aforementioned survey at Xindian. Both of these techniques (dog-leash and field-area collections) allow for approximate measures of sherd density but are appropriate for situations with different densities. Areas with very dense surface material must be sampled using a technique like dog-leash collection for the data to be manageable, whereas areas with very sparse material must incorporate finds across a larger area in order to provide sufficient data for evaluation (Banning, 2002; Burger et al., 2004; Caraher et al., 2006; Plog et al., 1978; Ur et al., 2011). There were very few artifacts anywhere in the Huizuiwa area beyond the bluff top. Only five artifacts total were collected from the 17 collection areas in the lower terrace. Because a couple of these were found on the terrace edge to the north across an erosion gulley, we believe part of the site may have been eroded away since the time of its occupation. 


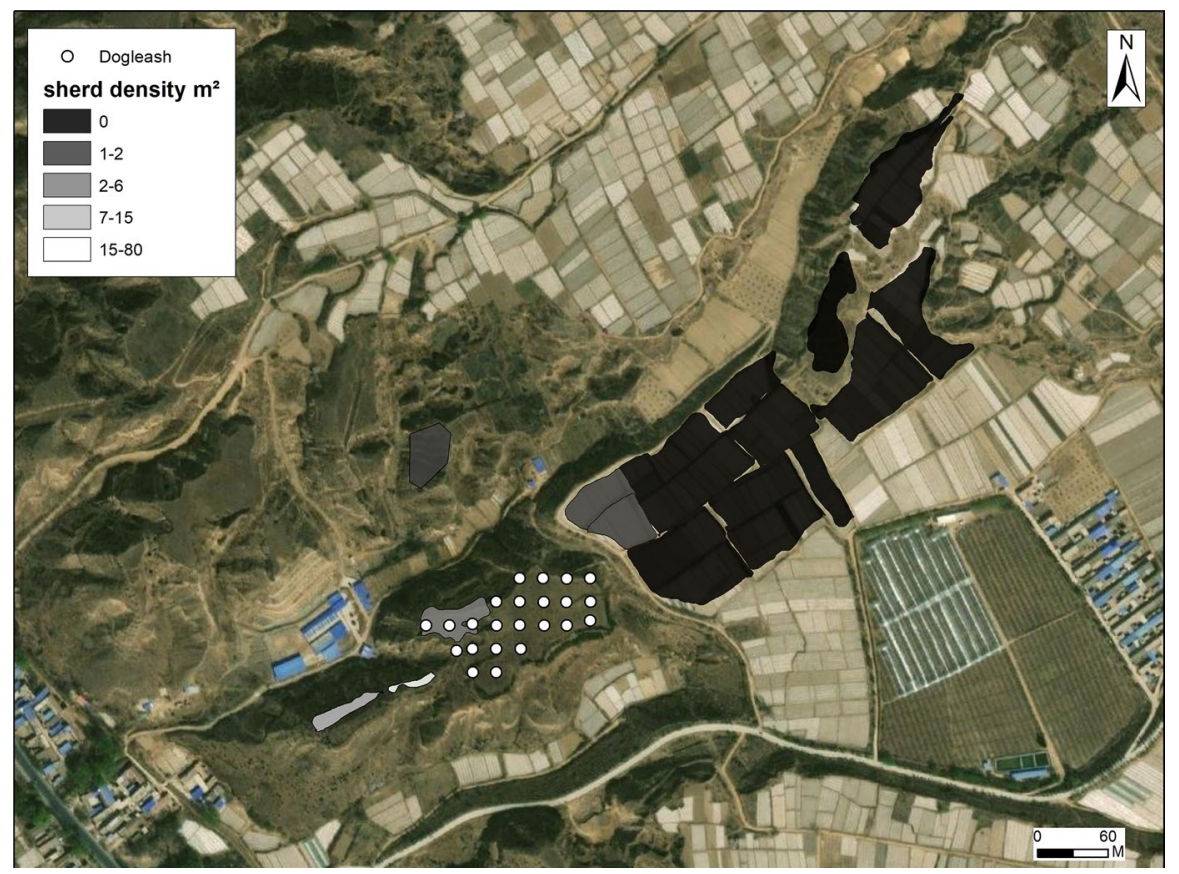

Fig. 5 Collection units and sherd density per $\mathrm{m}^{2}$ overlaid with location of dog-leash collection units (Color figure online)

As at Xindian, we calculated the density of sherds found in each survey collection unit at Huizuiwa and created a heuristic density map showing ceramic densities per $\mathrm{m}^{2}$ across the site. A clear separation can again be observed between the bluff top and the rest of the surveyed area. The results suggest an expectation of ceramic distribution in the northern direction, leading from the bluff to the test survey area (Fig. 6).

Geomorphological assessment of the region by Wang Hui of the Chinese Academy of Social Sciences, Institute of Archaeology in 2017 confirmed that a considerable portion of the original terrace had been removed during agricultural activity during recent decades. The terrace on the north side of the gully slopes slightly toward the river, but the terrain is extremely flat. On the northern edge of this platform, a fine sand layer was observed at $1.5 \mathrm{~m}$ under the current level as well as a red muddy strip with a thin layer of blue-gray silt. These finds indicate that water flows at the end of the accumulation of the platform. The soil is relatively dense, and the color is reddish, characteristics that suggest it may be a Holocene paleosol layer with aeolian loess as the parent material. This layer can also be clearly distinguished from the upper part of the section on the south side of the valley, and its color and texture are quite different from those of the lower part of the plateau. Through the investigation of the surrounding areas of the two gullies to the north and south sides of the site, the finds lead to a conclusion that a single geomorphological unit can be drawn from the terrain. However, the mesa 


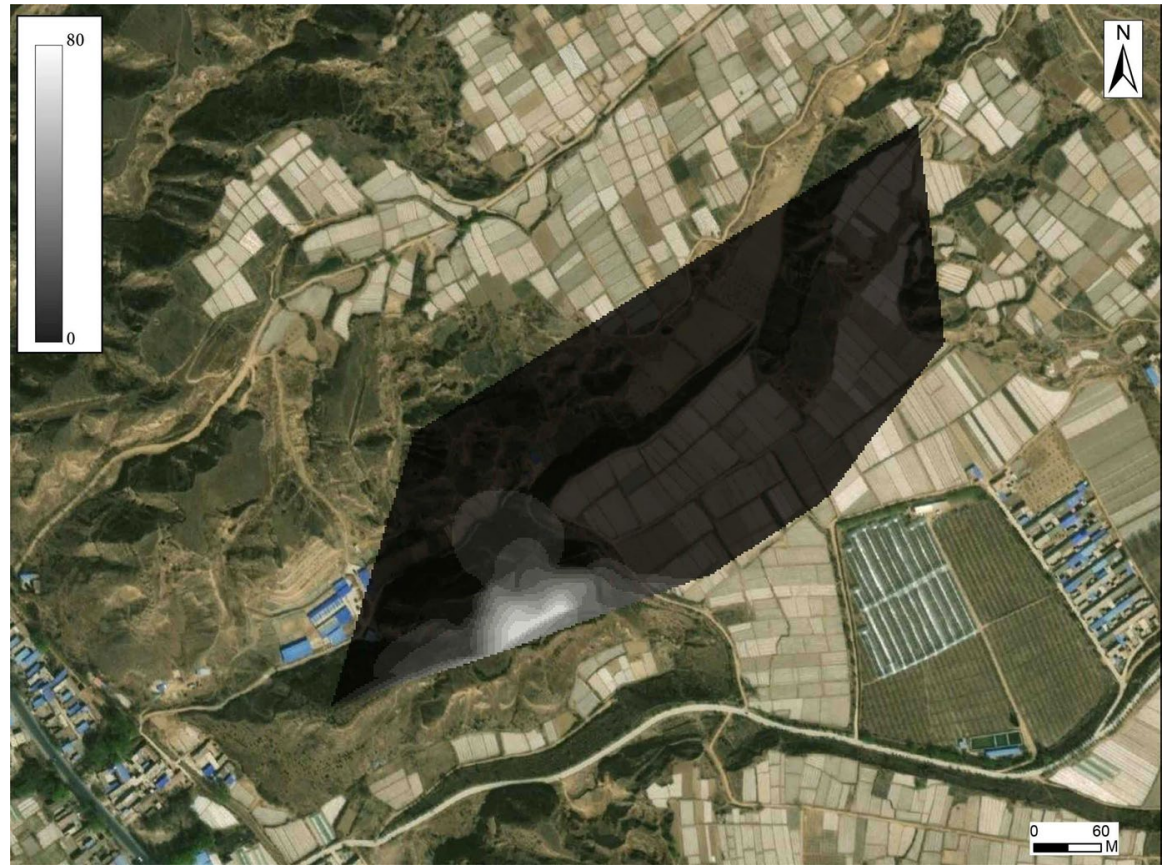

Fig. 6 Shading reflects sherd density per $\mathrm{m}^{2}$ across the HZW site according to the color ramp on the left site. Numbers represent sherds per unit, with white areas representing the densest locations (Color figure online)

section is composed of silt and clay with a gravel layer or a sand lens. Based on its color and less dense texture, the formation era is much later than the gravel layer in the high platform. Put plainly, the terrain on both sides of the gulley leading down from the site on its north side is practically identical. Even in places where preservation is worse, such as the area to the south of the site, the sedimentary sequence is consistent. This preservation situation is the result of erosion and more recent activity such as animal burrowing.

In order to investigate the potential presence of subsurface remains at the site, a small geophysical survey covering $3200 \mathrm{~m}^{2}$ across the surface of the bluff was undertaken over a single day in May of 2014. Such surveys have been successful in China and elsewhere for identifying a wide variety of anomalies related to archaeological materials, helping guide investigations, and aid in non-invasive site identification and interpretation (Gaffney \& Gater, 2006; Horsley, 2015; Kvamme, 2006). The survey was undertaken using a Geoscan FM256 Fluxgate Gradiometer with a stated sensitivity of $0.1 \mathrm{nT}$, although in practice the sensitivity of the instrument used is closer to $1 \mathrm{nT}$. Data grids of $20 \times 20 \mathrm{~m}$ were collected in a zigzag manner with a sample interval of $0.125 \mathrm{~m}$ and traverses every $0.5 \mathrm{~m}$. The instrument was reset between each grid to account for drift. Data were downloaded and processed using Geoplot 3.0; processing included clipping, destaggering, and interpolation in order to remove interference from ferrous debris and increase the visibility of potential 


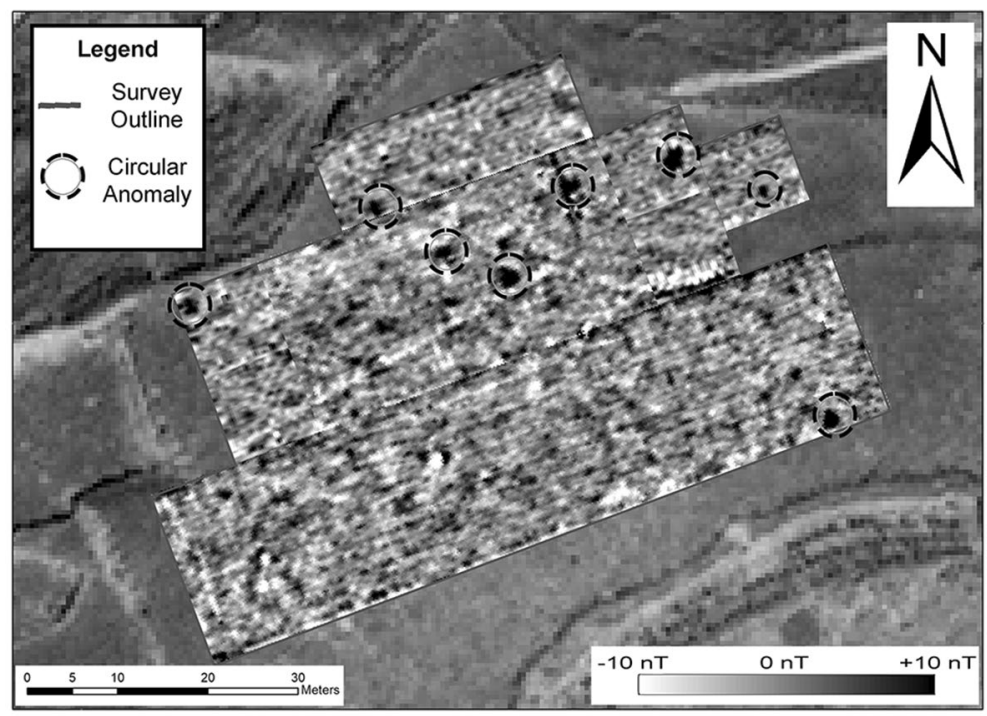

Fig. 7 Map of magnetometer survey area with yellow circles highlighting large anomalies. (A) anomaly chosen for excavation (Color figure online)

anomalies. Despite some NE to SW striping caused by the user during data collection, many subsurface anomalies are visible in the data. Anomalies potentially caused by archaeological features are clustered in the northern and eastern portions of the site and include at least eight circular anomalies with a range of 2-4 $\mathrm{m}$ in diameter and $+/-8-15 \mathrm{nT}$ in intensity (Fig. 7).

Based on comparison with similar anomalies recorded and excavated at Qijiaping (Womack et al., 2017) and Dayatou (Womack et al., 2019b), it appears that these were likely caused by trash pits. Hand auger testing of five anomalies revealed a mixture of soil changes, burnt earth, ash, bone, and sherds ranging from $40 \mathrm{~cm}$ to $2 \mathrm{~m}$ below the surface.

We believe that these features relate to the southern edge of an area of Xindian culture activity that may include residential and production remains, and that the majority of this part of the site has eroded away in the intervening millennia. To further explore these contexts, we conducted a small-scale trial excavation at the site in 2017.

\section{Excavation Methods and Results}

A $2 \times 2 \mathrm{~m}$ roughly circular anomaly that was identified during the geophysical survey as a potential trash pit was selected for targeted excavation. This anomaly was augered after identification in 2014, revealing burnt soil, ash, burnt material, bone, and sherds from 35 to $110 \mathrm{~cm}$ below the surface. The expectation was that these anomalies reflected deposits containing materials similar to those discovered in contexts at Qijiaping (Womack et al., 2017). We placed one $2 \times 2 \mathrm{~m}$ unit (17LH-T1) in a position to cut this anomaly. The excavations proceeded using a locus method 


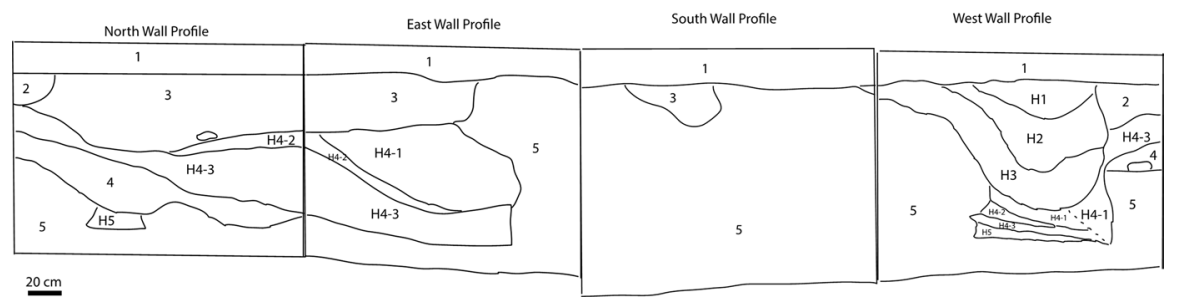

Fig. 8 The stratigraphy of the Huizuiwa site, showing locales from which samples were derived

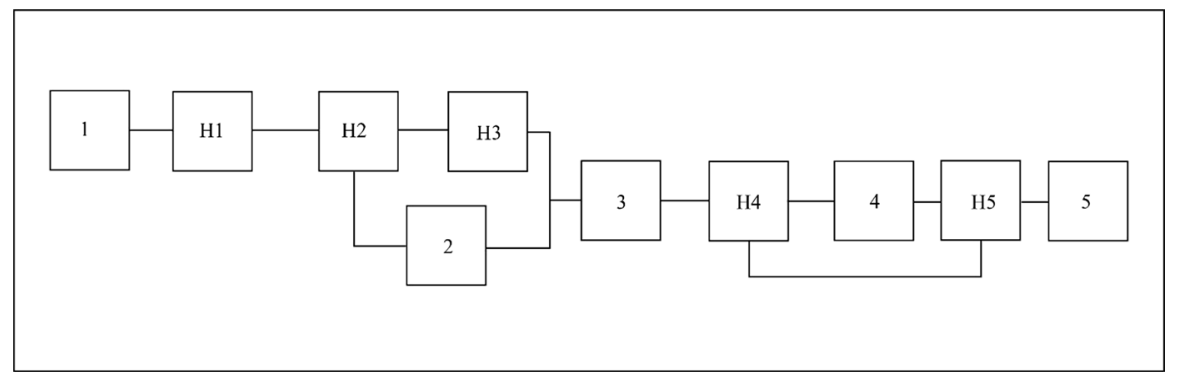

Fig. 9 Harris Matrix for the excavation of T1 at Huizuiwa

(adapted from Flinders Petrie, 1904; Joukowsky, 1986), in which all natural differences between sediments are excavated separately as different loci, but loci can also be used to arbitrarily separate sediments in different parts of a level, or a feature, or at different arbitrarily defined depths. The locus method allows for optimal control of both horizontal and vertical contexts for all finds, while maintaining the ability to recombine loci into natural stratigraphic components and features-the spatial components commonly used in Chinese archaeology for describing contextual relationships. All sediment was passed through a $5 \mathrm{~mm}$ screen and all small finds saved. We aimed to save roughly 101 of sediment from every locus for flotation, totaling roughly 335.51 .

The anomaly excavated at Huizuiwa revealed a succession of strata and features which appeared to be consistent with trash pits that had undergone multiple successive uses over time (Fig. 8). Separate episodes of deposition reflecting associated materials were quite difficult to differentiate upon first encounter. Consequently, we separated the material into 32 distinct loci during excavation (L1-L32), allowing for constant assessment of the stratigraphy without losing the association of the various finds recovered during excavation. These loci are each associated with one of the natural contexts discovered in the excavation, which include a succession of five stratigraphic levels and five interdigitated pits. The stratigraphic relationships among these contexts are described in the Harris Matrix in for Fig. 9 and Table 5.

As shown in the Harris Matrix and profile drawings, Pits H1, H2, Stratum 2, and Pits $\mathrm{H} 3$ and $\mathrm{H} 4$ comprise a series of superimposed deposits in more or less the same location. Layered between Pits H3 and H4 is Stratum 3, which spreads toward 
Table 5 Feature/stratum-locus relationships for 17LH-T1

\begin{tabular}{ll}
\hline Stratum/feature & Loci \\
\hline$(1)$ & $\mathrm{L} 1$ \\
$\mathrm{H} 1$ & $\mathrm{~L} 2 \rightarrow \mathrm{L} 3$ \\
$\mathrm{H} 2$ & $\mathrm{~L} 4 \rightarrow \mathrm{L} 9 \rightarrow \mathrm{L} 10$ \\
$(2)$ & $\mathrm{L} 5$ \\
$\mathrm{H} 3$ & $\mathrm{~L} 17 \rightarrow \mathrm{L} 12 / \mathrm{L} 13 /$ \\
& $\mathrm{L} 20 \rightarrow \mathrm{L} 21 \rightarrow \mathrm{L} 22 \rightarrow \mathrm{L} 25$ \\
$(3)$ & $\mathrm{L} 6 / \mathrm{L} 16 / \mathrm{L} 19 \rightarrow \mathrm{L} 8 / \mathrm{L} 18$ \\
$\mathrm{H} 4$ & $\mathrm{~L} 7 \rightarrow \mathrm{L} 23 \rightarrow \mathrm{L} 11 / \mathrm{L} 14 / \mathrm{L} 25 /$ \\
& $\mathrm{L} 26 / \mathrm{L} 27 \rightarrow \mathrm{L} 30 \rightarrow \mathrm{L} 31$ \\
$(4)$ & $\mathrm{L} 15 \rightarrow \mathrm{L} 28$ \\
H5 & $\mathrm{L} 29$ \\
$(5)$ & $\mathrm{L} 24 \rightarrow \mathrm{L} 32$ \\
\hline
\end{tabular}

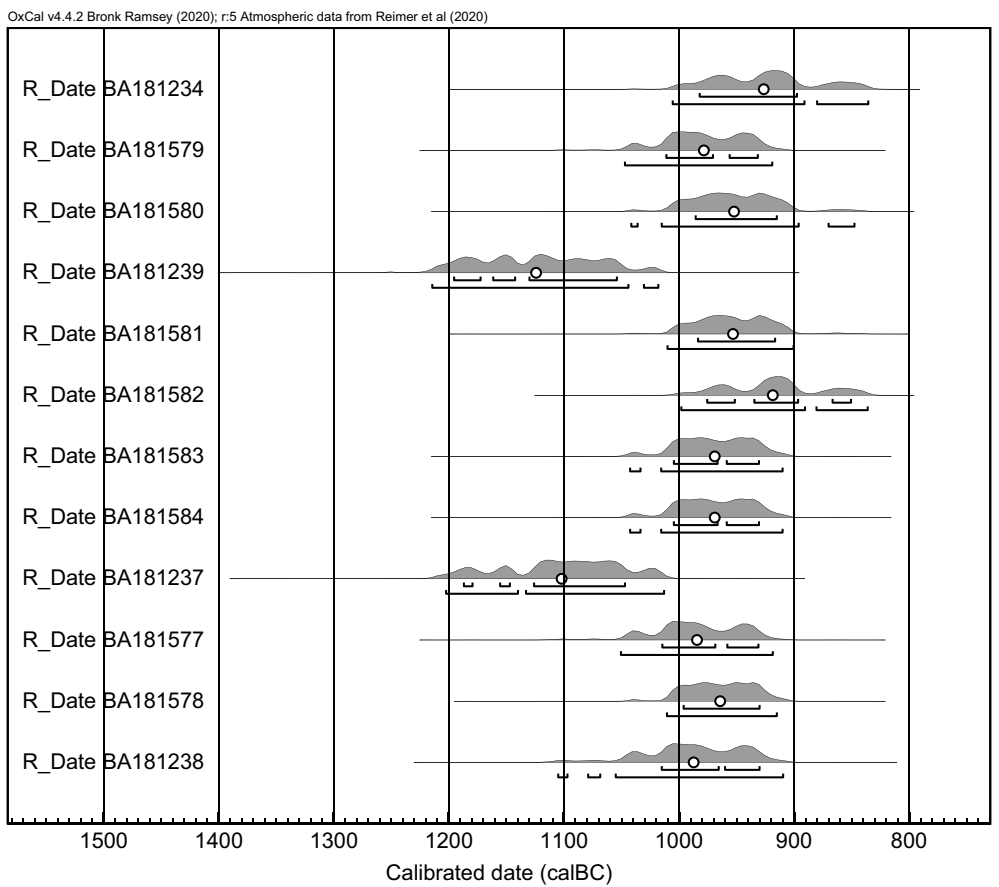

Fig. 10 Radiocarbon dates for 17LH-T2 (see Table 6 for details of these samples, listed in the same order)

the north and east beyond the area of most of these deposits. Pit H5, in contrast, was found below Stratum 4, and is seemingly more separate from the slightly later series of deposits. Stratum 5 is a natural, sterile deposit into which the pits and other deposits cut. 


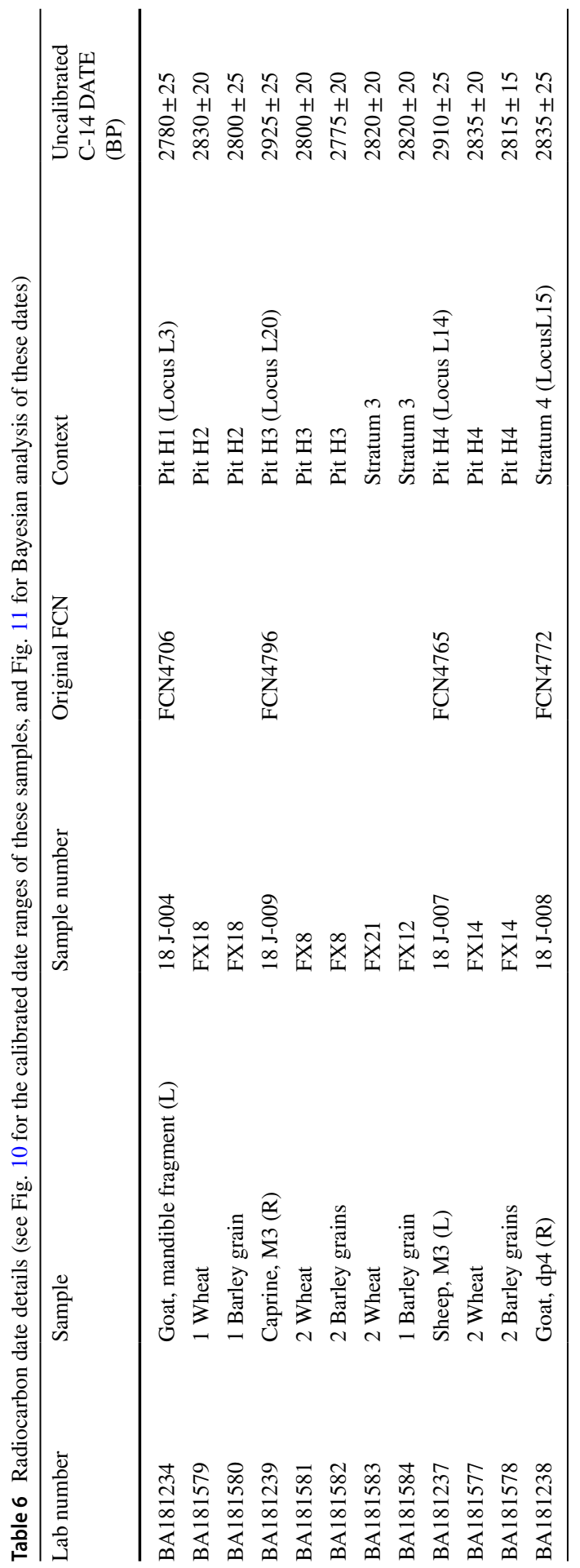


The archaeobotanical and zooarchaeological analyses described below provided samples that allow us to radiocarbon date these deposits-permitting both an estimation of the absolute chronology of the deposits excavated in 17LH-T1 and also an assessment of whether this series of strata and pit deposits were deposited relatively rapidly or over an extended period of time. The dates, shown in Fig. 10 and Table 6 in stratigraphic sequence, include four animal bones and eight dates on short-lived archaeobotanical remains. With the exception of two dates from animal bones which are anomalously early (samples BA181239 and BA181237), most of the dates are clearly within the tenth century calibrated BC, around $2900 \mathrm{BP}$, and the dates seem to be in generally stratigraphic order, with the earlier dates lower in the stratigraphic sequence.

To further tighten the chronology of these deposits, we subjected the stratified dates to Bayesian analysis (Bronk, 2009; Buck et al., 1991; Otárola-Castillo $\&$ Torquato, 2018). Figure 11a, b shows the results of the Bayesian evaluation of these dates. In Fig. 11a we have retained the two seemingly anomalous bone dates in their appropriate stratigraphic position, a process the considerably constrains both the $1 \sigma$ and $2 \sigma$ likelihood of the dates for these two samples (as shown by the dark gray curves in Fig. 11). In Fig. 11b we remove these two samples. The 'phases' in the figures represent the stratigraphic contexts for which we have dates (in sequence from earliest to latest: Level 4, Pit H4, Level 3, Pits H3, H2 and H1). Based on this assessment, the entire sequence of deposits within the excavation trench fits within the tenth century BC (i.e., between 2950 and 2850 BP). The earliest pit deposits are decidedly in the first half of the century, while the sequence of superimposed pitlike deposits comprising $\mathrm{H} 3, \mathrm{H} 2$, and $\mathrm{H} 1$ clearly dates to the middle to late part of the century. Accordingly, the sequence suggests that the deposits are from roughly the same few decades, perhaps reflecting a series of similar, repeated depositional activities.

\section{Ceramics}

A large number of ceramic sherds (1200) were recovered from the five pits (H1-H5) and three layers (Layers 2-4). They were analyzed and classified in the same manner as the Xindian finds (see above). The finds are largely identifiable as Xindian-type wares, with only 7 potential Qijia-type sherds (from H1, Layers 2 and 3, and the surface), 1 sherd resembling Siwa ceramics, and 5 later-period sherds from the surface survey.

The ceramics are mostly thick-bodied, often coarse, low-fired, and were probably coil-built. This applies to the Xindian-type wares from all contexts. Throughout all layers, over $70 \%$ of them have undergone firing in an oxidizing atmosphere, resulting in often mottled combination in the light brown/yellow/ orange/red spectrum (Table 7). A slightly higher percentage in reduction-fired grey wares can be observed in the earliest deposit, (i.e., Layer 4), suggesting a possible slight change in firing technology or color preferences. Only very few sherds are black or dark brown in color, but these mostly seem to be the outcome 
A

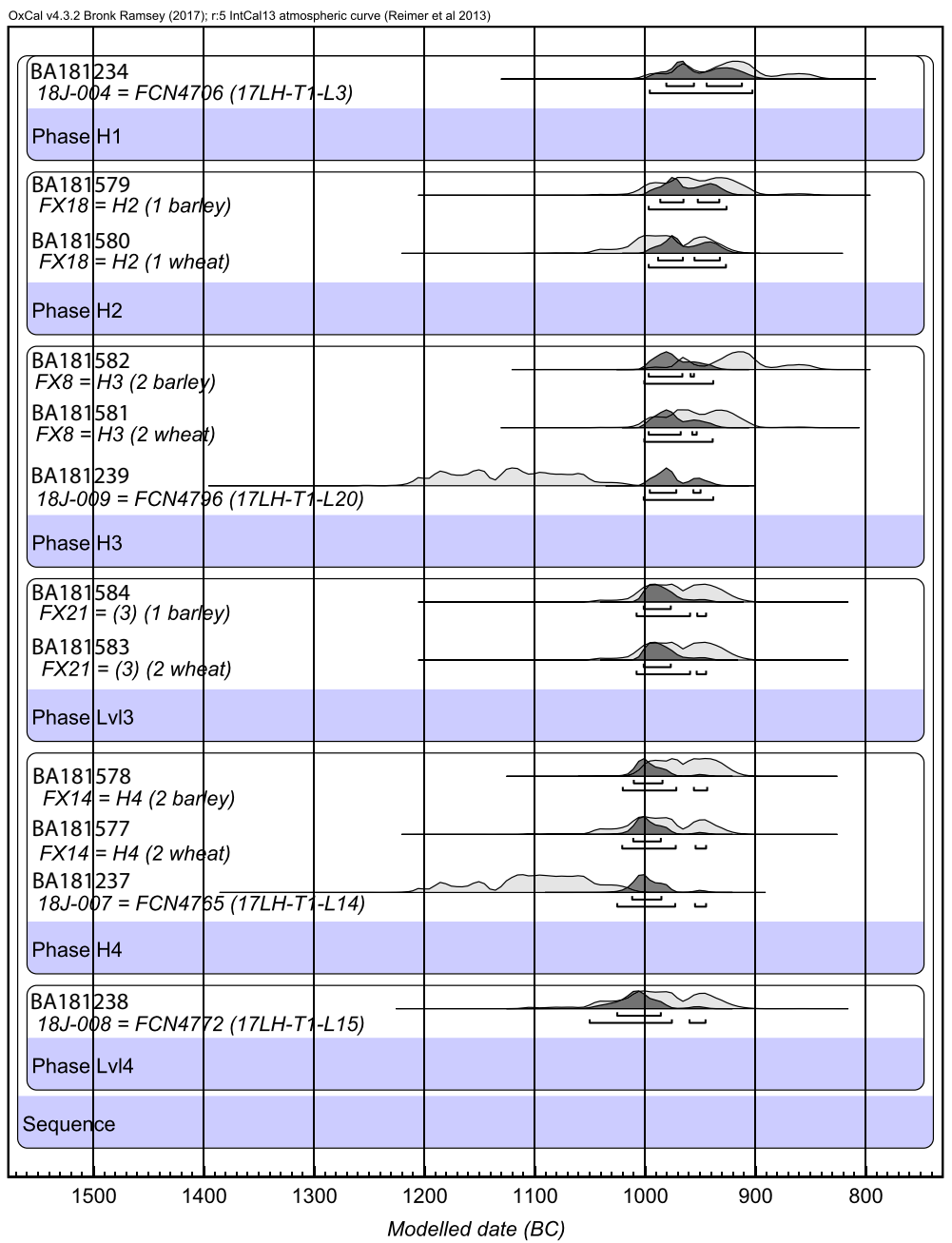

Fig. 11 A Bayesian analysis of dates reported in Table 6 including two outlier dates. B Bayesian analysis with anomalous dates removed. Phases represent the different stratigraphic contexts from which the samples were recovered (Color figure online)

of secondary firing through cooking or other processes rather than intentional production of dark-colored wares (see Appendix II for details).

In terms of ware quality, fine wares occur in relatively low percentages throughout all layers with higher numbers in the earlier layers and features (up to 25\%) and lower in the later layers and features (as low as 12.5\%). The remaining material has high percentages of sand-sized and larger inclusions, but lower percentages of material with coarse sand inclusions than would be expected (Table 8). The wares may be coarser than the macroscopic differentiation between fine medium and coarse sand would suggest, simply because the 
B

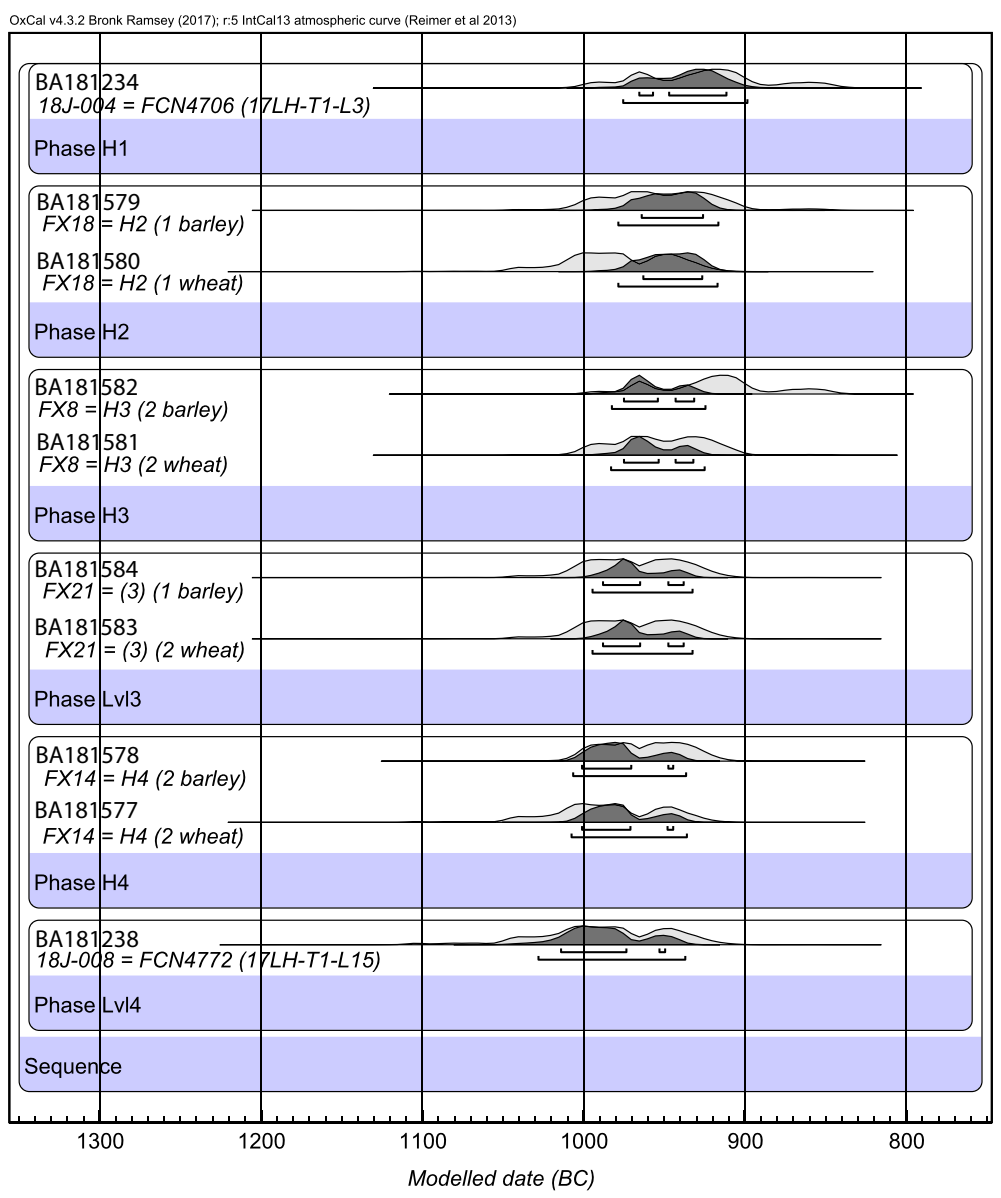

Fig. 11 (continued)

assessment of actual coarseness (i.e., amount and size of above silt-sized inclusions) would require microscopic analysis.

The majority of ceramics seem to have received some form of treatment and often a combination of different forms of decoration (Table 8). Most common are slip, black paint, and fine cord marks, which can appear combined or independently. Less frequent are brown, red, or white pigments, coarse or medium cordmarks, appliqué bands, incisions, line marks, or various impressed patterns. Polish has been reported in a few cases but is notoriously difficult to identify macroscopically.

Most common decoration motifs are broad horizontal painted black bands applied to the upper part of the vessel with thin wavy or zigzag bands in between and vertical wavy or zigzag bands on the two opposite sides of the lower part of the vessel body. These decorations were mostly applied to flat-bottomed 


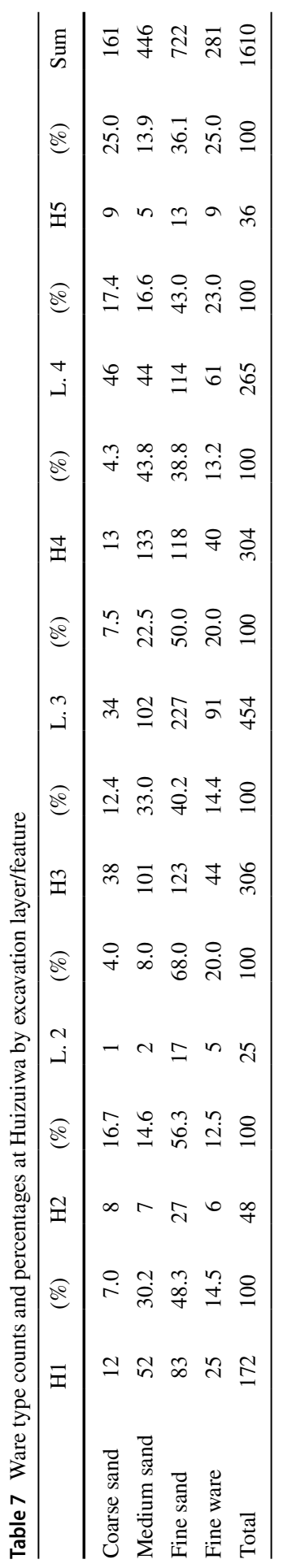


Table 8 Decoration and surface treatment type counts and percentages at Huizuiwa by excavation layer/ feature

\begin{tabular}{lrrrrrrrrrr}
\hline & H1 & H2 & Layer 2 & H3 & Layer 3 & H4 & Layer 4 & H5 & SUM & Percentage (\%) \\
\hline Plain & 72 & 11 & 10 & 71 & 133 & 82 & 76 & 13 & 468 & 24.2 \\
Slipped & 17 & 13 & 4 & 84 & 65 & 46 & 39 & 7 & 275 & 14.2 \\
Polished & 2 & 0 & 0 & 1 & 1 & 1 & 6 & 0 & 11 & 0.6 \\
Painted & 46 & 21 & 8 & 116 & 188 & 105 & 109 & 14 & 607 & 31.5 \\
Cordmarked & 45 & 19 & 5 & 91 & 137 & 105 & 86 & 12 & 500 & 25.9 \\
Impressed & 0 & 0 & 1 & 1 & 0 & 0 & 0 & 0 & 2 & 0.1 \\
Appliqué & 6 & 4 & 0 & 12 & 12 & 6 & 11 & 0 & 51 & 2.6 \\
Folded rim & 0 & 0 & 0 & 4 & 0 & 0 & 0 & 0 & 4 & 0.2 \\
Incisions & 2 & 0 & 2 & 1 & 0 & 4 & 2 & 1 & 12 & 0.6 \\
Sum & 190 & 68 & 30 & 381 & 536 & 349 & 329 & 47 & 1930 & 100.00 \\
\hline
\end{tabular}

A sherd can have more than one type of decoration, leading to a higher number of occurrences $(n=1930)$ than overall sherd number $(n=1610)$. Percentages are based on the number of sherds with the referenced treatment

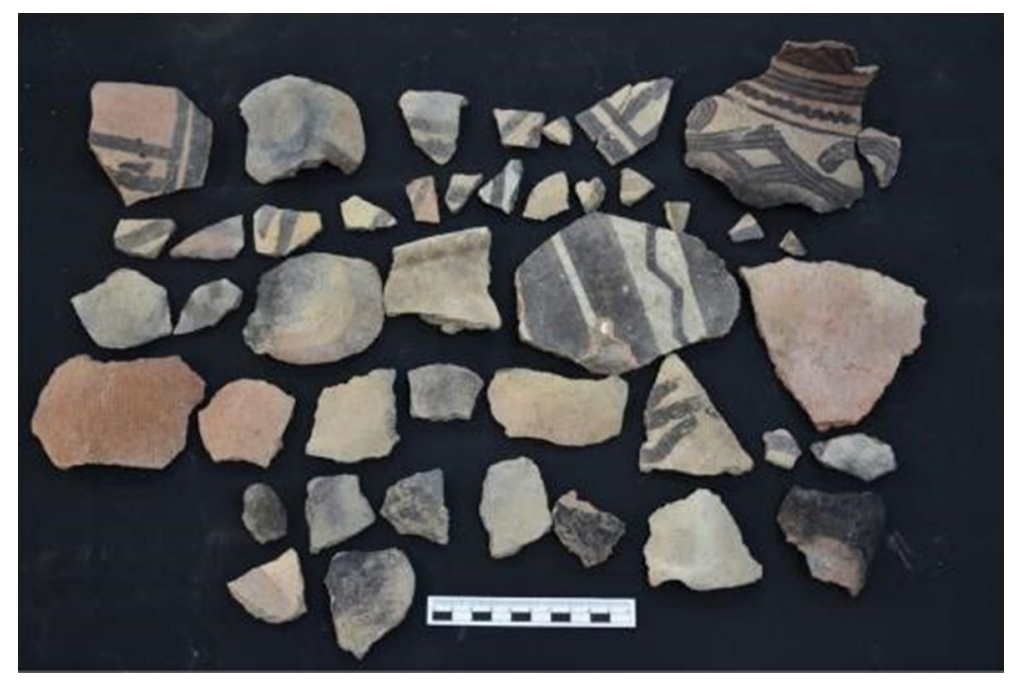

Fig. 12 Decorated ceramics from pit H4 (Color figure online)

double-handled jars. Other identifiable vessel forms include flat-bottomed jars of sometimes very large and sometimes small dimensions (judged by the degree of curvature of the vessel bodies) that may carry one or two band handles with or without appliqué or painted decoration on the handles or vessel body. Another identifiable vessel type are tripods (16 examples identified) of grey or red color covered in fine or coarser cordmarks and sometimes carrying appliqué bands but never slip or paint (see Supplemental Files, Appendix II for details). The ceramic repertoire thus closely resembles that of Yijiachuan and related sites 
Table 9 Huizuiwa identified taxa

NISP \%NISP MNI NISP by context

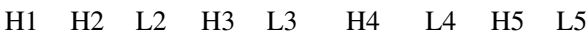

\begin{tabular}{|c|c|c|c|c|c|c|c|c|c|c|c|c|}
\hline \multicolumn{13}{|l|}{ Non-Mammals } \\
\hline Gastropod shell & 3 & 0.5 & 3 & & & & 1 & 1 & 1 & & & \\
\hline Small bird & 1 & 0.2 & 1 & & & & & & 1 & & & \\
\hline Medium bird & 1 & 0.2 & 1 & & & & & 1 & & & & \\
\hline \multicolumn{13}{|l|}{ Mammals } \\
\hline Rodentia & 1 & 0.2 & 1 & & & & 1 & & & & & \\
\hline Small rodent & 35 & 6.3 & 7 & 1 & 2 & & 12 & 6 & 10 & 4 & & \\
\hline Medium rodent & 5 & 0.9 & 2 & & & & 2 & 2 & 1 & & & \\
\hline \multicolumn{13}{|l|}{ Carnivora } \\
\hline Canidae & 31 & 5.6 & 2 & & 3 & & 6 & 11 & 10 & & 1 & \\
\hline Canis familiaris (dog) & 3 & 0.5 & 1 & & & & 1 & 2 & & & & \\
\hline Artiodactyla & 14 & 2.5 & 1 & & 4 & & & 6 & 4 & & & \\
\hline Medium artiodactyl & 2 & 0.4 & 1 & & & & 2 & & & & & \\
\hline Large artiodactyl & 1 & 0.2 & 1 & & & & 1 & & & & & \\
\hline \multicolumn{13}{|l|}{ Suidae } \\
\hline Sus scrofa (pig) & 4 & 0.7 & 1 & & & & & 3 & 1 & & & \\
\hline Cervidae & 3 & 0.5 & 1 & & & & 1 & 2 & & & & \\
\hline Medium cervid (deer) & 1 & 0.2 & 1 & 1 & & & & & & & & \\
\hline Bovidae & 6 & 1.1 & 1 & 1 & & & 1 & 2 & & & 2 & \\
\hline Large bovine & 14 & 2.5 & 1 & & 1 & & & 9 & 3 & 1 & & \\
\hline Bos taurus (cattle) & 2 & 0.4 & 1 & & & & & 1 & & 1 & & \\
\hline Medium Bovid & 294 & 52.7 & 3 & 7 & 11 & 8 & 56 & 75 & 108 & 25 & 4 & \\
\hline Ovis aries (sheep) & 13 & 2.3 & 2 & & & & 2 & 4 & 7 & & & \\
\hline Capra hircus (goat) & 23 & 4.1 & 6 & 2 & & & 9 & 3 & 7 & 2 & & \\
\hline Ovis/Capra (sheep/goat) & 20 & 3.6 & 2 & 1 & 3 & & 9 & 3 & 4 & & & \\
\hline Medium bovid or cervid & 77 & 13.8 & 3 & 15 & 13 & & 7 & 10 & 22 & 10 & & \\
\hline Large bovine or cervid & 4 & 0.7 & 1 & & & & & 2 & 2 & & & \\
\hline TOTAL & 558 & 100 & & 28 & 37 & 8 & 111 & 143 & 181 & 43 & 7 & 0 \\
\hline \multicolumn{13}{|l|}{ Unidentified specimens } \\
\hline Unid. S. Mammal & 63 & & & 4 & 7 & & 7 & 25 & 13 & 4 & 3 & \\
\hline Unid. S. or M. Mammal & 1 & & & & & & 1 & & & & & \\
\hline Unid. M. Mammal & 1140 & & & 47 & 46 & 7 & 165 & 354 & 414 & 91 & 10 & 6 \\
\hline Unid. M or L. Mammal & 3 & & & & & 1 & & 1 & 1 & & & \\
\hline Unid. L. Mammal & 44 & & & 2 & 1 & 1 & 14 & 14 & 10 & 2 & & \\
\hline Unid. Mammal & 3335 & & & 253 & 156 & 36 & 503 & 809 & 1229 & 236 & 105 & 8 \\
\hline Total & 4586 & & & 306 & 210 & 45 & 690 & 1203 & 1667 & 333 & 118 & 14 \\
\hline Total specimens & 5144 & & & 334 & 247 & 53 & 801 & 1346 & 1848 & 376 & 125 & 14 \\
\hline
\end{tabular}

L1 through L5 are stratigraphic layers. H1 through H5 are pit features. Unid. = Unidentified; S. = small; M.=medium; L.=Large; Small mammals are hare or fox-sized, medium mammals are dog or sheepsized, and large mammals are cattle-sized 
as well as the Xindian-type wares found at the Xindian type site with no clear differences between the various layers and features excavated at Huizuiwa itself (Fig. 12).

\section{Fauna}

Animal bones recovered during excavation were analyzed at the Gansu Provincial Institute of Archaeology using standard zooarchaeological reference guides. Some specimens were also taken to the Zooarchaeology Laboratory at the Center for Scientific Archaeology, Institute of Archaeology, Chinese Academy of Social Science in Beijing for further identification using comparative collections there. Bones found during flotation in the heavy fraction have not yet been analyzed. For a full discussion of zooarchaeological methods and the raw zooarchaeological data, see Brunson et al. (2020).

The numbers of identified specimens (NISP) and minimum number of individuals (MNI) for each taxon are listed in Table 9 (also see Supplemental files, Huizuiwa_zooarchaeology_sup). Domestic mammals represent the most commonly identified taxa. Sheep (Ovis aries) and goats (Capra hircus) are the most common domesticates. Caprine bones lacking clear morphological markers such as those described in Zeder and Lapham (2010) and Zeder and Pilaar (2010) were only identified as 'Ovis/Capra,' or to the broader taxonomic category of 'medium bovid.' While it is likely that most specimens identified as 'medium bovids' are domestic sheep and goats, it is important to note that Northwestern China is also home to several native bovids including gazelle, serow, argali, goral, Siberian ibex, Tibetan antelope, and blue sheep/bharal. There are not standard ways to distinguish between the bones of these taxa (although see Wang, 2017), and so fragmentary cases were identified conservatively. Together, specimens identified as Ovis, Capra, Ovis/Capra, and medium bovid make up about $85 \%$ of the assemblage.

Other domesticates include dogs (Canis familiaris), cattle (Bos taurus), and pigs (Sus scrofa). It is likely that all of the specimens identified as canids are domestic dogs, although it is possible that wild canids such as wolves and dhole were present in the region as well. Specimens identified as 'large bovines' are most likely domestic cattle. Distinguishing between the bones of domestic and wild Chinese bovines is challenging, and there is still a possibility that some of these specimens belong to wild cattle or water buffalo. The small number of pig bones in the assemblage makes it difficult to comment on their domestication status. They are most likely domestic pigs rather than wild boar because at least two of the four pig bones come from sub-adults (identified pig bones include a lower permanent incisor, a fragment of a proximal metapodial II or V, a fragment of a metapodial II or V with an unfused distal epiphysis, and an unfused proximal epiphysis of a left tibia). While people occasionally raised dogs, cattle, and pigs, it is clear that animal use at Huizuiwa was focused on caprine pastoralism.

Very few wild animal bones were identified at Huizuiwa. Non-mammals include two bird bones and a few small gastropod shells that are commonly found in loess deposits in the region and were probably not consumed by people. Rodents in the 
assemblage are likely intrusive. The TRAP team observed many rodent burrows during our excavations, and most of the rodent bones probably come from animals that died in their burrows. A limited number of deer bones were identified. These include a third phalanx from a medium sized cervid and three fragments of antler, two of which were worked into antler objects. The most common medium sized cervid in the area is sika deer (Cervus nippon). It is likely that the deer phalanx belongs to this species. The small number of deer remains and the parts of the body they represent suggest that deer were not frequently hunted at Huizuiwa, if at all. The deer remains may have come from antlers and skins (phalanges are often retained in skins) traded in to the site. The paucity of cervid remains is noteworthy given that deer imagery is understood to be a common feature of Xindian ceramic decorations at other sites such as Xiaohandi (Qinghaisheng 1995).

A detailed discussion of taphonomy is beyond the scope of this article, but the faunal assemblage does appear to be heavily fragmented, possibly indicating that people processed bones for marrow and grease. The sample size of caprine bones and teeth that can be used to assign ages at death is too small to construct mortality curves; however, our preliminary observations indicate that sheep and goats may have been slaughtered in different ways. Several of the goats died before six months of age. None of the sheep died before one year of age.

We identified 28 worked bone objects at Huizuiwa, the most notable of which is a divinatory oracle bone (FCN4750) made from a right caprine scapula. Figure 13 shows the oracle bone during excavation at the bottom of pit $\mathrm{H} 2$ where it was found along with several large stones. Almost all of the animal bones in the Huizuiwa faunal assemblage were small, broken fragments. This scapula was one of the few complete skeletal elements uncovered, suggesting that it was intentionally placed intact at the bottom of $\mathrm{H} 2$ rather than deposited in the pit along with other refuse from butchery and bone working activities. The scapula has a large discoloration in the

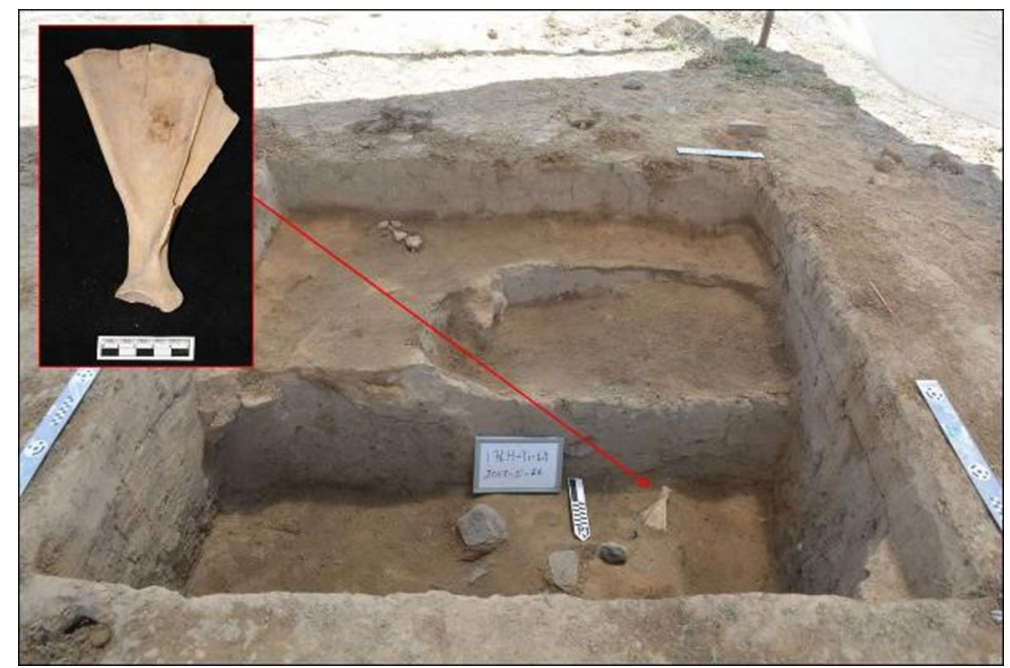

Fig. 13 Oracle bone (FCN4750) in situ at the bottom of H2 (Color figure online) 
Table 10 Features from which flotation samples were derived

\begin{tabular}{lll}
\hline Feature & Number of samples & Liters sampled \\
\hline H1 & 2 & 13.5 \\
H2 & 3 & 23.5 \\
Layer 2 & 1 & 11 \\
H3 & 6 & 53 \\
Layer 3 & 4 & 33 \\
H4 & 6 & 47 \\
Layer 4 & 1 & 5 \\
H5 & 1 & 9 \\
Layer 5 & 1 & 7.5 \\
\hline
\end{tabular}

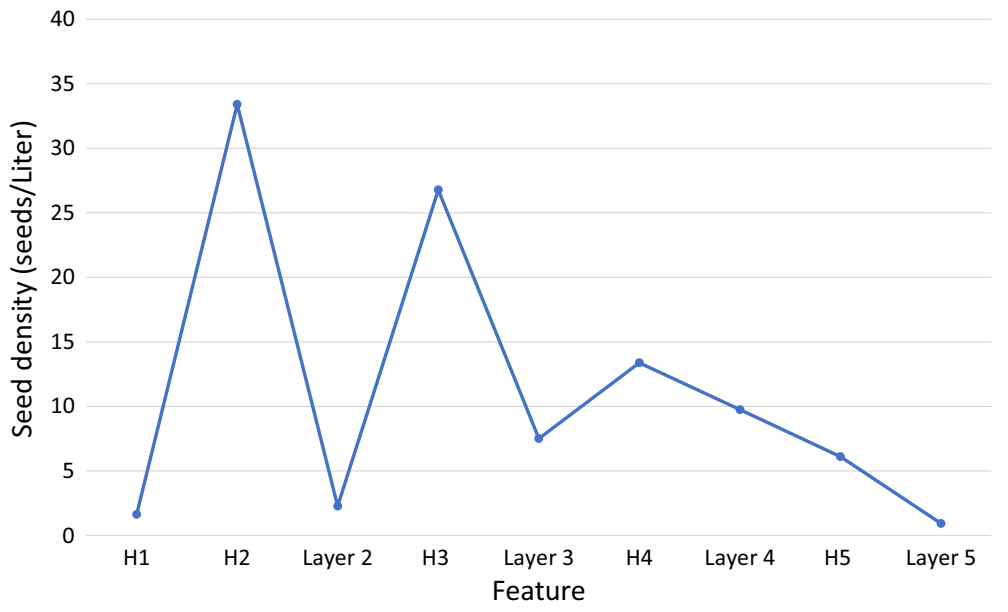

Fig. 14 Seed density per stratigraphic unit (Color figure online)

center of the blade caused by heating. This burn mark is not as clear as the burn marks on most oracle bones, and there is not a clear crack. It may represent a failed attempt to burn the bone for divination.

\section{Flora}

Archaeobotanical samples were floated using standard bucket flotation (d'Alpoim Guedes \& Spengler 2014) at the Gansu Provincial Institute of Archaeology and the light fraction was caught on a $0.25 \mathrm{~mm}$ nylon mesh. Once in the laboratory, samples were sieved into $2 \mathrm{~mm}, 1 \mathrm{~mm}, 0.5 \mathrm{~mm}$, and $0.25 \mathrm{~mm}$ fractions that were examined separately under Olympus light microscopes. Wood charcoal was pulled from the $2 \mathrm{~mm}$ fraction and remaining fractions were scanned for seeds. Seed fragments were collected from the $2 \mathrm{~mm}$ and $1 \mathrm{~mm}$ fractions, though 


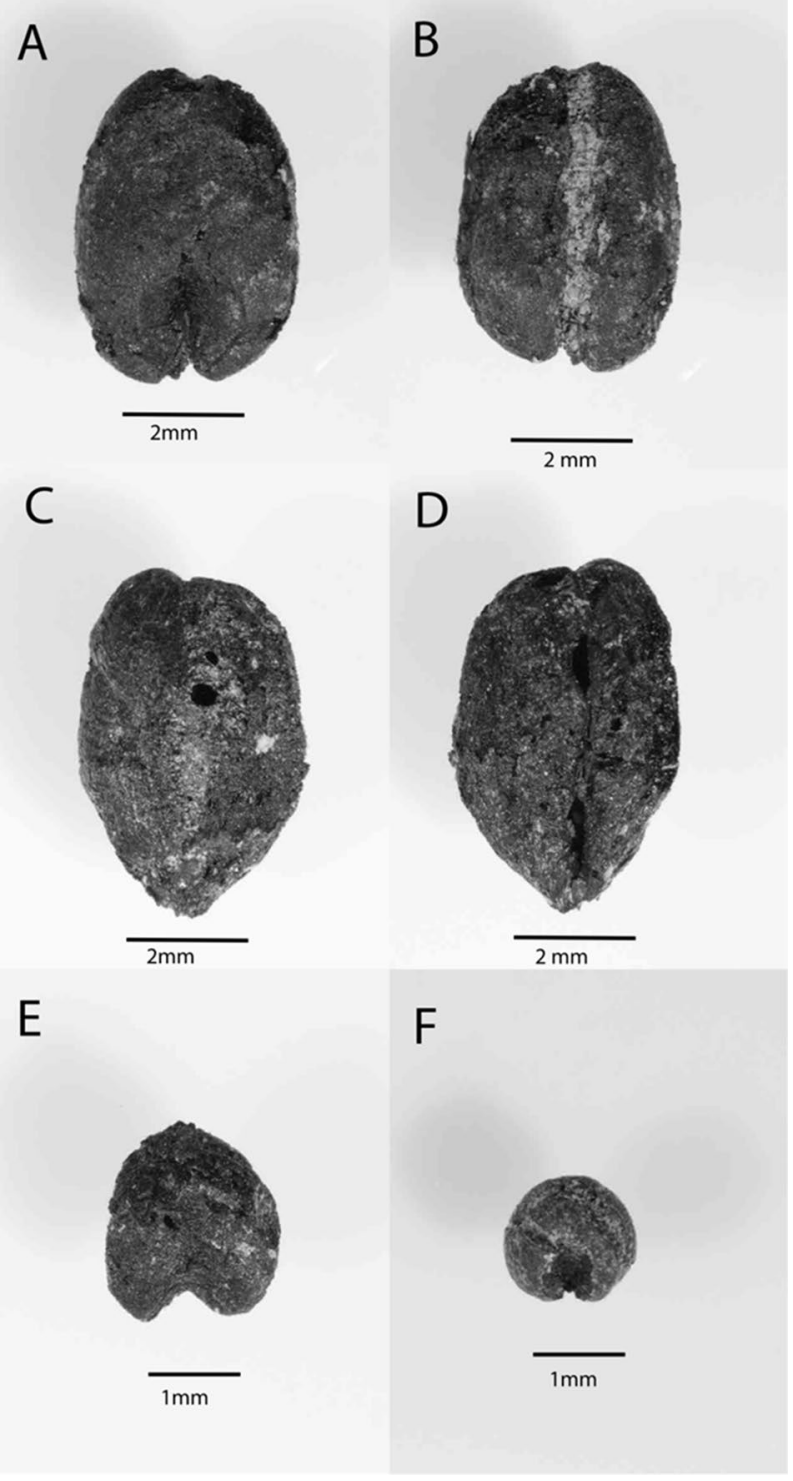

Fig. 15 Key domesticates unearthed from the Huizuiwa site: a wheat, Triticum sp. (dorsal side); b wheat Triticum sp. (ventral side); c barley Hordeum vulgare (dorsal side); d barley Hordeum vulgare (ventral side); e broomcorn millet (Panicum miliaceum); f foxtail millet (Setaria italica)

seed fragments were collected from the $0.5 \mathrm{~mm}$ fraction if they were particularly recognizable. The $0.25 \mathrm{~mm}$ fraction was scanned to reveal if rice spikelet bases might be present; however, none were recovered. Identifications were made using the reference collections of Shandong University, the Paleoethnobotany 


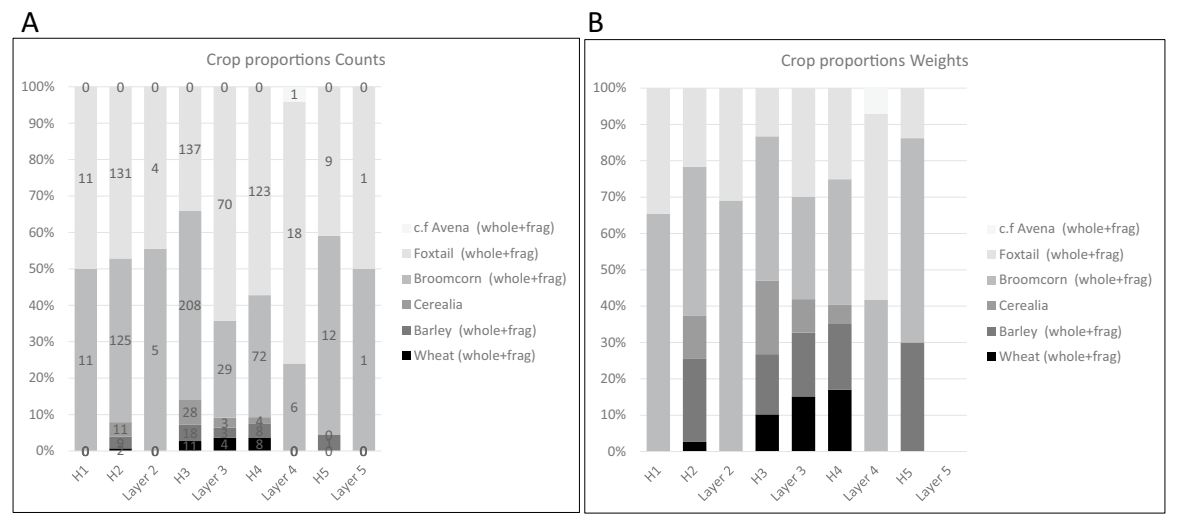

Fig. 16 Crop proportions at Huizuiwa: $\mathbf{A}$ by count and $\mathbf{B}$ by weight (Color figure online)

Laboratory at the University of California, San Diego as well as a local flora (Wu et al., 2006) and prior archaeobotanical publications from the region (Fan, 2016; Flad et al., 2010; Jiang et al., 2017; Yang 2015; Zhang, 2013; Zhang et al., 2017; Zhao, 2003, 2010) and for different domesticated cereals (Fuller, 2006; Jacomet, 2006).

The highest density of seeds per liter was derived from pits $\mathrm{H} 2, \mathrm{H} 3$ and H4. H5 and $\mathrm{H} 1$ had lower counts of archaeobotanical remains, as did all the stratigraphic layers. Layer 4 had a higher density of remains than Layers 2 and 5 (Table 10 and Fig. 14; Also see Supplemental Files, Huizuiwa_bot_sup).

Several key domestic taxa were recovered from the samples we analyzed (Fig. 15). These include foxtail millet (Setaria italica), broomcorn millet (Panicum miliaceum), barley (Hordeum vulgare) and wheat (Triticum sp.). Only one rachis fragment was recovered from the site; it belonged to a naked type of wheat (Triticum aestivum var. nudum). One specimen of what might be oat (Avena sp.) or a related species of wild grass was also recovered. Specimens that were likely either wheat or barley but were too poorly preserved to be identified were termed Cerealia to indicate that they were either wheat or barley but could not be confidently distinguished.

In research in China, archaeobotanical remains are generally presented exclusively as counts. However, relying on counts to reveal potential contributions to the diet can be misleading as caryopsis size differs substantially between crops such as millets and larger grains like wheat and barley. If we consider only counts (Fig. 16a), wheat and barley appear to be present in smaller quantities than millets: something that might lead one to the conclusion that they constituted only a minor component of the diet. If one considers the contribution of these elements to the diet in terms of weight (Fig. 16b), the picture changes somewhat: wheat and barley appear to constitute roughly $40 \%$ of the total crop weights at the site. Broomcorn and foxtail millet still dominate the assemblage in layers or features with overall low seed density, and while it is possible that this is due to their smaller size making them more likely to migrate throughout the stratigraphy of the site, the short date range between the different pits makes this seem less plausible. 


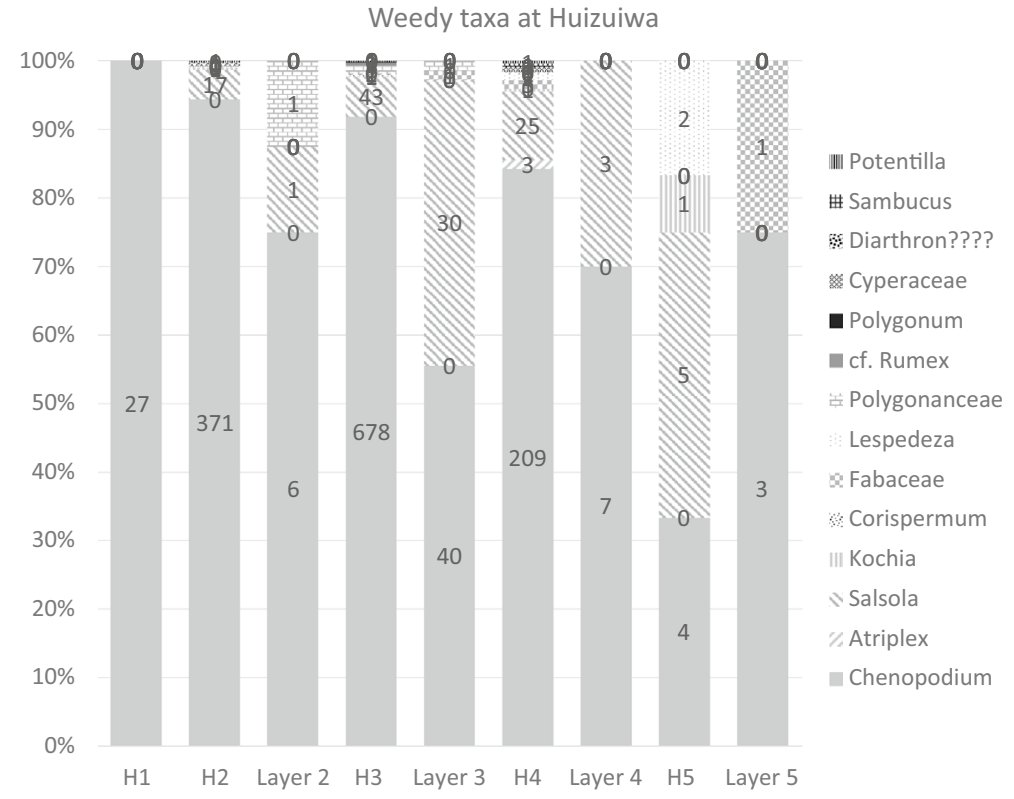

Fig. 17 Proportions of key taxa of weeds identified at Huizuiwa (Color figure online)

Several weedy taxa were also recovered from the site. These include Chenopodium sp., Digitaria sp., Atriplex sp., Salsola sp., Kochia sp., Corispermum sp., Lespedeza sp., Rumex sp., Polygonum sp., Sambucus sp. and Potentilla sp., an unidentified wild pooid grass, a wild Fabaceae and some unidentified specimens of Polygonaceae and Cyperaceae (Figs. 17 and 18). Chenopodium sp. and Salsola sp. are the most numerous weeds identified in the assemblage. Some taxa require further work on identification, particularly the wild Fabaceae unearthed at the site. There are over 167 genera and 1600 species of Fabaceae present in the region, making their ultimate identification a challenging task that requires further work. Weedy taxa recovered in the ashpit, particularly those such as members of the Cyperaceae family, which grow wild and occupy river banks, as well as small-seeded Fabaceae, may have found their way into the archaeobotanical assemblage following animal consumption and subsequent burning of animal dung (Miller \& Smart, 1984). It is possible that animals like sheep and goats foraged their diet alongside rivers and along hilltops where wild Fabaceae grow. Indeed, conglomerates of what appeared to be either goat or sheep dung were also found in our assemblages; however, the high weights and counts of wood charcoal suggest that the inhabitants of the site relied primarily on wood for fuel.

In addition, we recovered a total of 13 unidentified specimens, all of which occurred in very low numbers with the exception of unidentified specimen $a$ and $b$. 


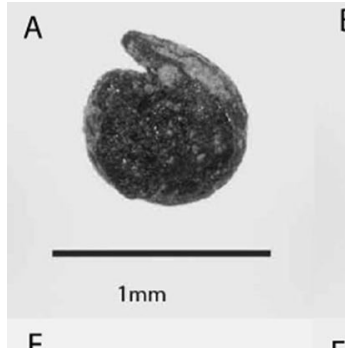

$E$

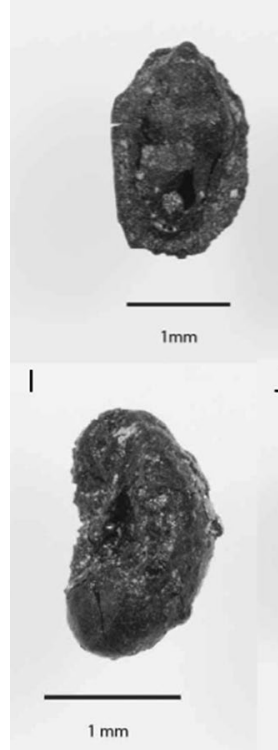

J
B

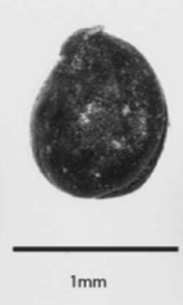

$\mathrm{F}$

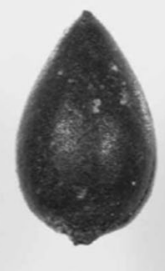

$1 \mathrm{~mm}$
C

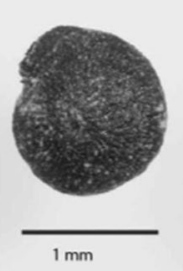

G

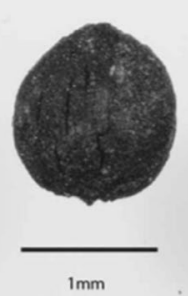

D

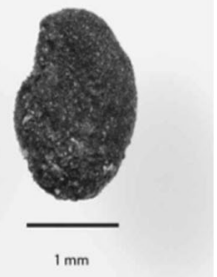

$\mathrm{H}$

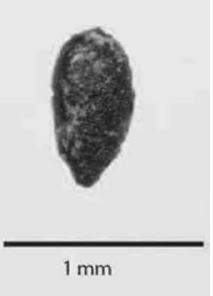

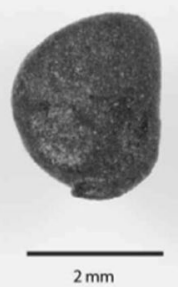

K
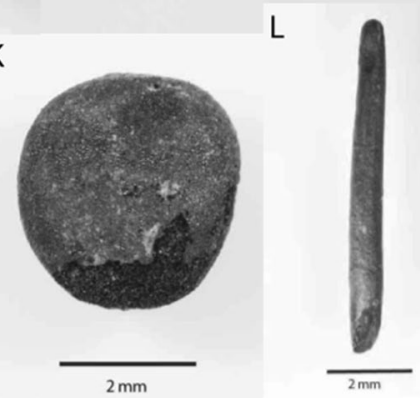

M

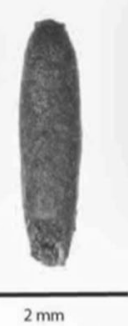

Fig. 18 Key weed taxa identified at Huizuiwa: a Atriplex sp.; b Chenopodium sp. c Chenopodium cf. hybridium; d Lespedeza sp.; e Corispermum sp.; f cf. Polygonum; g Scripus/Carex type, h Digitaria sp.; i Fabaceae type 1 (cf. Medicago); j Fabaceae type 2, k Fabaceae type 3; l pooid grass type 1; $\mathbf{m}$ pooid grass type 2

\section{Discussion and Conclusion}

A large number of studies have reconstructed the second millennium BC economy of the upper Yellow River as one dominated by pastoralism—possibly even involving semi-sedentary populations and more ephemeral settlements. In part, this assumption of pastoralism may reflect a tendency to perceive prehistoric societies inhabiting the upper Yellow River valley as others to their 'Chinese' counterparts situated in the Central Plains and adjacent regions. Yet, to date, research has relied on data derived from a limited number of excavated cemeteries, cursory survey data and a handful of residential contexts, severely limiting the ability to evaluate these models. 
The work discussed in this paper brings together systematic survey results and their analysis in ArcGIS, magnetometer investigation, excavation and the analytical exploration of ceramic, faunal and floral remains, including a series of stratified radiocarbon dates. Together, they offer windows into past lifeways of the communities inhabiting these regions during this time. Our finds, while limited, further enable us to evaluate existing narratives of 2 nd millennium $\mathrm{BC}$ societies in the region. Mostly, they caution against approaches that would view this large region as uniformly occupied by identical communities who subsisted on the same economic practices.

\section{Xindian Culture Ceramics}

Previously, Xindian, as a ceramic tradition, was defined mostly on the basis of grave assemblages. We identified only few differences between the ceramics in the two areas of Xindian. Thus, even while very coarse ware is relatively rare at Xindian A (the cemetery) and rather common at Xindian B (the settlement site), fine wares are very common in both contexts, suggesting that there are no major differences between wares for burial and those used in everyday life. Additionally, there are no major differences in the frequency of different decoration motifs or surface treatments between settlement and cemetery.

As was found at Xindian, the Huizuiwa ceramic material suggests that the ceramics interred in graves were not hugely different from those found in the residential units. Comparison between the two sites reveals local-specific preferences, and there appears to be considerable regional variation in the range of ware types, decorations, and forms, with marked differences observable between sites in the Tao River valley, Gansu, and Qinghai in particular (Shui, 2001; Jaffe \& Hein, 2020). Even similar kinds of Xindian painted decorations and vessel forms, such as the double-bandhandled jars, appear with a variety of different ware types and other surface treatments, suggesting a host of local potting traditions among these ceramic groups.

\section{Site Layout and Occupation}

At the site of Xindian our work finds a possible affirmation for Andersson's initial identification of the specific roles of Xindian A and B as a cemetery and residential area respectively. Our survey at Xindian revealed a far higher concentration of ceramic finds in the latter and based on our density model we predict the site indeed expanded further west along the slope and not north towards the cemetery. This settlement layout, an elevated residential locus relatively small in size and in a defensible position, is observed at Huizuiwa as well, as indicated by the results of both the geophysical work and survey results. At Huizuiwa the residential site may have extended further across the now eroded bluff, but the overall settlement size does not seem to have been very large. We interpret the bluff top location of these small settlements as the result of a preference for defensible location with good visibility. The defensiveness of Xindian sites like Xindian and Huizuiwa may reflect an awareness more of the potential dangers presented by social dynamics than any particular 
environmental changes, but for now these sites, at least, do not show any clear evidence of concerns beyond those of villagers focused on their relatively local needs and relationships. Our current dates for Huizuiwa suggest that the thick deposits there were created by a community that existed for less than one hundred years. The thick accumulation of deposits may indicate intensive activity at this discrete settlement, reflecting a village that was involved in mixed agro-pastoralism.

\section{Subsistence: Flora and Fauna}

Faunal evidence at Huizuiwa suggests that herding domestic sheep and goats was an important subsistence and economic activity. Domestic dogs at Huizuiwa could have been used as guard dogs and pets, but could also have been used as herding dogs, given the strong evidence for sheep and goat herding at the site. Only a few wild animal and non-mammal remains were identified in the assemblage, which suggests that people at Huizuiwa rarely hunted wild animals such as deer. Further analysis of the flotation heavy fraction is still needed, but the complete absence of fish bones is surprising given the site's proximity to the Tao river. While certain taphonomic processes could be behind the lack of fish, the fact that all excavated soil was sifted and sorted, and no remains were found in flotation samples or at Qijiaping (Womack et al., 2017) make this possibility less likely. Based on the current data, therefore, we believe fish were not commonly exploited. Additionally, we can assume that caprines at Huizuiwa were used for a variety of resources including meat, milk, and possibly wool. Zooarchaeological evidence for wool exploitation has been found at other Early Bronze Age sites (Brunson et al., 2016; Li et al., 2014; You et al., 2016), and wool was an important part of pastoralist economies in Northwest China (You et al., 2016). Our discovery of a caprine oracle bone indicates that sheep and goats were also important for ritual activities during the Xindian period. The remains do not obviously correspond, however, to a mobile or semi-sedentary residential pattern-during the couple of centuries it was occupied a series of pits were dug one into the other, where intensive burning and large amounts of ceramic were found, instead suggesting a commitment to place and multi-decade investment in settlement continuity.

Related to this, the archaeobotanical evidence reflects a reliance on grains, including a combination of millets and the domesticates that were introduced into this region in the millennium or so prior to these Xindian culture remains. When grain weights are taken into account then wheat and barley appear in roughly equal numbers to millet. Thus, we do not see a transition to wheat and barley agriculture as has been observed in areas of higher altitude (d'Alpoim Guedes and Bocinsky 2018; d'Alpoim Guedes, 2016) — at least not in this particular set of samples_-nor do we see a sole reliance on millet. Instead, the data indicate that farmers in this area multicropped a diverse range of grasses, possibly a strategy to mitigate risk in the face of variable climatic conditions. Similar strategies of crop diversification have been noted for other areas of the world, for instance the planting of maslins, or mixtures of seeds, in the Aegean (Marston, 2011). The uptake of western Eurasian domesticates (such as wheat and barley) across East Asia did not occur in a uniform fashion, 
and farmers likely adapted their choice of crops to the local conditions surrounding their site. The residents at Huizuiwa, at least, exploited a mixture of domesticated grains, and were invested in both plant and animal-based agricultural activities.

\section{Conclusion}

The results of our work do not show a whole-scale transition in subsistence and cultural practices following the $4.2 \mathrm{k} \mathrm{BP}$ event. When compared with results at Qijiaping and other earlier sites, Xindian activities show selective uptake of new crops and animals, but also a continuation of older practices. Xindian activities in this region took advantage of the opportunities presented by environmental changes, social dynamics, and interregional interaction that were available in an ever-changing world. Xindian communities in the broader western regions show no evidence of being incorporated into the centralizing political dynamics of Bronze Age China further to the east.

The Tao River Archaeology Project has aimed to create a model for gathering robust archaeological information that can solidify our base-line understanding of economic, technological, and social practices in the third through early first millennia BC. We hope that future research, which similarly incorporates survey data, geophysical prospection, and excavations, will increase our understanding of these domains of activity, and further refine the chronology of settlements and communities in this region, allowing the further exploration of broader social dynamics in prehistoric Northwestern China.

Supplementary Information The online version contains supplementary material available at https://doi. org/10.1007/s10963-021-09160-w.

Acknowledgements The survey and excavation work reported in this paper was supported by research permits granted by the Gansu Provincial Bureau of Culture and the National Bureau of Cultural Heritage of China, and research support by the American School of Prehistoric Research, Harvard University Asia Center, and the Gansu Provincial Institute of Archaeology and Cultural Relics. Katherine Brunson would like to acknowledge the support of the Joukowsky Institute for Archaeology and the Ancient World at Brown University and the Center for Scientific Archaeology at the Institute of Archaeology, Chinese Academy of Social Sciences. We wish to thank three anonymous reviewers from the Journal of World Prehistory for their helpful comments as well as editorial feedback and support from Tim Taylor and Michael Frachetti. We also appreciate the local support in Lintao County from administrators and local residents who enabled the fieldwork reported here.

Open Access This article is licensed under a Creative Commons Attribution 4.0 International License, which permits use, sharing, adaptation, distribution and reproduction in any medium or format, as long as you give appropriate credit to the original author(s) and the source, provide a link to the Creative Commons licence, and indicate if changes were made. The images or other third party material in this article are included in the article's Creative Commons licence, unless indicated otherwise in a credit line to the material. If material is not included in the article's Creative Commons licence and your intended use is not permitted by statutory regulation or exceeds the permitted use, you will need to obtain permission directly from the copyright holder. To view a copy of this licence, visit http://creativecommons.org/licen ses/by/4.0/. 


\section{References}

An Z. 安志敏. (1956). Gansu Yuangu Wenhua Jiqi Youguan de Jige Wenti 甘肃远古文化及其有关的几 个问题 (Questions regarding Gansu's ancient Culture). Kaogu Tongxun 考古通讯 [Archaeological Reports], 1956(6), 9-19.

An Z. (1999). The Bronze Age in eastern parts of Central Asia. In A. H. Dani \& V. M. Masson (Eds.) History of civilizations of Central Asia (pp. 319-336). Delhi: Motilal Banarsidass.

An, C., Tang, L., Barton, L., \& Chen, F. (2005). Climate change and cultural response around $4000 \mathrm{Cal}$ Yr BP in the western part of Chinese loess plateau. Quaternary Research, 63(3), 347-352.

Andersson, J. G. (1925). Preliminary report on archaeological research in Kansu. Memoirs of the Geological Survey of China (Series a), 5, 1-51.

Andersson, J. G. (1943). Researches into the prehistory of the Chinese. Bulletin of the Museum of Far Eastern Antiquities. Museum of Far Eastern Antiquities.

Bagley, R. (1999). Shang archaeology. In M. Loewe \& E. L. Shaughnessy (Eds.), The Cambridge history of ancient China: From the origins of civilization to 221 BC (pp. 124-241). Cambridge University Press.

Banning, E. B. (2002). Archaeological survey. Kluwer.

Barton, L., Newsome, S. D., Chen, F. H., Wang, H., Guilderson, T. P., \& Bettinger, R. L. (2009). Agricultural origins and the isotopic identity of domestication in northern China. Proceedings of the National Academy of Sciences USA, 106(14), 5523-5528.

Booth, R. K., Jackson, S. T., Forman, S. L., Kutzbach, J., Bettis, E., Kreig, J., \& Wright, D. (2005). A severe centennial-scale drought in mid-continental North America 4200 years ago and apparent global linkages. The Holocene, 15, 321-328.

Bronk, R. C. (2009). Bayesian analysis of radiocarbon dates. Radiocarbon, 51(1), 337-360.

Brunson, K., He, N., \& Dai, X. (2016). Sheep, cattle, and specialization: New zooarchaeological perspectives on the Taosi Longshan. International Journal of Osteoarchaeology, 26, 460-475.

Brunson, K., Ren, L., Zhao, X., Dong, X., Wang, H., Zhou, J., \& Flad, R. (2020). Zooarchaeology, ancient mtDNA, and radiocarbon dating provide new evidence for the emergence of domestic cattle and caprines in the Tao River Valley of Gansu Province, northwest China. Journal of Archaeological Science Reports, 31, 102262.

Buck, C. E., Kenworthy, J. B., Litton, C. D., \& Smith, A. F. (1991). Combining archaeological and radiocarbon information: A Bayesian approach to calibration. Antiquity, 65(249), 808-821.

Burger, O., Todd, L. C., Burnett, P., Stohlgren, T. J., \& Stephens, D. (2004). Multi-scale and nestedintensity sampling techniques for archaeological survey. Journal of Field Archaeology, 29, 409-423.

Cai, J., Chiang, C. H., Breitenbach, S. F. M., Tan, L. C., Cheng, H., Edwards, R. L., \& An, Z. S. (2017). Holocene moisture changes in western China, Central Asia, inferred from stalagmites. Quaternary Science Reviews, 158, 15-28.

Campbell, R. (2014). Archaeology of the Chinese Bronze Age: From Erlitou to Anyang. Cotsen Institute of Archaeology Press.

Caraher, W. R., Nakassis, D., \& Pettegrew, D. K. (2006). Siteless survey and intensive data collection in an artifact-rich environment: Case studies from eastern Corinthia, Greece. Journal of Mediterranean Archaeology, 19(1), 7-43.

Chang, K. C. (1986). The archaeology of ancient China (4th ed.). Yale University Press.

Chen, X., Fang, Y., Hu, Y., Hou, Y., Lü, P., Yuan, J., Song, G., Fuller, B., \& Richards, M. (2015). Isotopic reconstruction of the late Longshan period (c. 4200-3900 BP) dietary complexity before the onset of state-level societies at the Wadian site in the Ying River Valley, Central Plains, China. International Journal of Osteoarchaeology, 26, 808-817.

Cheng, H. 陈洪海. (2006). Ganqing diqu shiqian eenhua zhong de erceng raoluan zang bianxi甘青地 区史前文化中的二次扰乱葬辨析 (Analysis of prehistoric disturbed secondary burials in the Gansu-Qinghai regions). Kaogu 考古 [Archaeology], 2006(1), 54-68.

Cheung, C., Jing, Z., Tang, J, \& Richards, M. (2017). Social dynamics in Early Bronze Age China: A multi-isotope approach. Journal of Archaeological Science: Reports, 16, 90-101.

Chifeng, International Collaborative Archaeological Research Project. (2011). Settlement patterns in the Chifeng region. University of Pittsburgh Center for Comparative Archaeology. 
Contreras, D. (Ed.). (2016). The archaeology of human-environment interactions: Strategies for investigating anthropogenic landscapes, dynamic environments, and climate change in the human past. Routledge.

d'Alpoim Guedes, J. (2016). Model building, model testing, and the spread of agriculture to the Tibetan Plateau. Archaeological Research in Asia, 5, 16-23.

d'Alpoim Guedes, J., \& Bocinsky, R. K. (2018). Climate change stimulated agricultural innovation and exchange across Asia. Science Advances, 4(10), 4491-4503.

d'Alpoim Guedes, J., Crabtree, S., Bocinsky, R., \& Kohler, T. A. (2016a). Twenty-first century approaches to ancient problems: Climate and society. Proceedings of the National Academy of Sciences USA, 113(51), 14483-14491.

d'Alpoim Guedes, J., Lu, H., Hein, A., \& Schmidt, A. (2015). Early evidence for the use of wheat and barley as staple crops on the margins of the Tibetan Plateau. Proceedings of the National Academy of Sciences USA, 112(18), 5625-5630.

d'Alpoim Guedes, J., Lu, H., Li, Y., Spengler, R., Wu, X., \& Aldenderfer, M. (2013). Moving agriculture on the Tibetan Plateau: The archaeobotanical evidence. Archaeological and Anthropological Sciences, 6, 255-269.

d'Alpoim Guedes, J., Manning, S. W., \& Bocinsky, R. K. (2016b). A 5,500-year model of changing crop niches on the Tibetan Plateau. Current Anthropology, 57(4), 517-522.

d'Alpoim Guedes, J. A., \& Spengler, R. (2014). Sampling strategies in paleoethnobotany. In J. M. Marston, J. D. A. Guedes, \& C. Warinner (Eds.), Method and theory in paleoethnobotany (pp. 77-94). University of Colorado Press.

Dai, L., Balasse, M., Yuan, J., Zhao, C., Hu, Y., \& Vigne, J. (2016a). Cattle and sheep raising and millet growing in the Longshan age in central China: Stable isotope investigation at the Xinzhai site. Quaternary International, 426, 145-157.

Dai, L., Li, Z., Zhao, C., Yuan, J., Hou, L., Wang, C., Fuller, B., \& Hu, Y. (2016b). An isotopic perspective on animal husbandry at the Xinzhai site during the initial stage of the legendary Xia Dynasty (2070-1600 BC). International Journal of Osteoarchaeology, 26, 885-896.

Dalfes, H., Kukla, G., \& Weiss, H., (Eds.). (1997). Third millennium BC climate change and Old World collapse. NATO ASI series 1,49 . Springer.

DeMenocal, P. B. (2001). Cultural responses to climate change during the Late Holocene. Science, 292, $667-673$.

Dong, G., Xin, J., Elston, R., Chen, F., Li, S., Wang, L., Ci, L., \& An, C. (2013). Spatial and temporal variety of prehistoric human settlement and its influencing factors in the Upper Yellow River Valley, Qinghai Province, China. Journal of Archaeological Science, 40, 2358-2546.

Dong, G., Yang, Y., Liu, X., Li, H., Cui, Y., Wang, H., Chen, G., Dodson, J., \& Chen, F. (2017). Prehistoric trans-continental cultural exchange in the Hexi Corridor, northwest China. The Holocene, 28(4), 621-628.

Dong, G., Zhang, F., Liu, F., Zhang, D., Zhou, A., Yang, Y., \& Wang, G. (2018). Multiple evidences indicate no relationship between prehistoric disasters in Lajia site and outburst flood in Upper Yellow River Valley, China. China Earth Sciences, 61(4), 441-449.

Dykoski, C. A., Edwards, R. L., Cheng, H., Yuan, D., Cai, Y., Zhang, M., Lin, Y., Qing, J., An, Z., \& Revenaugh, J. (2005). A high-resolution, absolute-dated Holocene and deglacial Asian monsoon record from Dongge cave, China. Earth and Planetary Science Letters, 233(1-2), 71-86.

Fan, X. 范宪军. (2016). Xicheng yizhi tanhua zhiwu yicun fenxi 西城驿遗址炭化植物遗存分析 (Report on the archaeobotanical remains from the Xicheng site). Lishi Wenhua Xueyuan 历史文化学院. Shandong University.

Fiskesjö, M., \& Chen, X. (2004). China before China: Johan Gunnar Andersson, Ding Wenjiang, and the discovery of China's prehistory. Museum of Far Eastern Antiquities.

Fitzgerald-Huber, L. (1995). Qijia and Erlitou: The question of contacts with distant cultures. Early China, 20, 17-68.

Flad, R. (2017). Where did the Silk Road come from? In M. Szonyi \& J. Rudolph (Eds.), The China questions (pp. 237-243). Harvard University Press.

Flad, R., Li, S., Wu, X., \& Zhao, Z. (2010). Early wheat in China: Results from new studies at Donghuishan in the Hexi Corridor. The Holocene, 20(6), 955-965.

Flinders Petrie, W. M. (1904). Methods and aims in archaeology. MacMillan.

Frachetti, M. (2012). Multi-regional emergence of mobile pastoralism and non-uniform instutional complexity across Eurasia. Current Anthropology, 53(1), 2-38.

Fuller, D. (2006). A millet atlas: Some identification guidance. University College London. 
Gaffney, C. F., \& Gater, J. (2006). Revealing the buried past: Geophysics for archaeologists. Tempus.

Gansusheng Bowuguan Wenwu Gongzuodui 甘肃省博物馆文物工作队. (1981). Gansu Dong xiang yatou Xindian wenhua muzang qingliji 甘肃东乡崖头辛店文化墓葬清理记 (Documentation and publication of the Yatou Xindina culture cemetery site in Dong county, Gansu). Wenwu 文物 [Cultural Relics], 1981(2), 16-20.

Gansusheng Wenwu Gongzuodui 甘肅省文物工作隊 \& Beijing Daxue Kaoguxi Gansu Shixizu 北京 大學考古係甘肅實習組. (1988). Gansu Linxia Lianhuatai Xindian wenhua muzang fajue baogao (Excavation report of Xindina culture site of Lianhuatai in Linxia, Gansu) 甘肅臨夏蓮花台辛店 文化墓葬發掘報告. Wenwu 文物 [Cultural Relics], 1988(3), 7-20.

Gansu Sheng Wenwu Kaogu Yanjiusuo 甘肃省文物考古研究所 \& Xibei Daxue Wenhua Yichan Yu Kaoguxue Yanjiu Zhongxin 西北大学文化遗产与考古学研究中心. (2009). Gansu Lintan Xian Mogou Qijia wenhua mudi 甘肃临潭县磨沟齐家文化墓地 (The Qijia culture cemetery at Mogou in Lintan County, Gansu). Kaogu 考古 [Archaeology], 2009(6), 10-17, 100-103.

Gao D. 高东陆 \& Wu P. 吴平. (1984). Qinghai Jingnei faxian de shiguanmu 青海境内发现的石棺墓 (The discovery of a stone coffin grave in Qinghai). Qinghai kaogu xuehui huikan 青海考古学会会 刊 [Proceedings of the Qinghai Archaeological Society], 1984(6), 4-12.

Goldsmith, Y., Broecker, W., Xu, H., Polissar, P., deMenocal, P., Porat, N., Lan, J., Cheng, P., Zhou, W., \& An, Z. (2017). Northward extent of East Asian monsoon covaries with intensity on orbital and millennial timescales. Proceedings of the National Academy of Sciences USA, 114, 1817-1821.

Haldon, J., Mordechai, L., Newfield, T., Chase, A., Izdebski, A., Guzowski, P., Labuhn, I., \& Roberts, N. (2018). History meets Palaeoscience: Consilience and collaboration in studying past societal responses to environmental change. Proceedings of the National Academy of Sciences USA, $115(13), 3210-3218$.

Han, J. (2012). 'The Painted Pottery Road' and early Sino-Western cultural exchanges. Anabasis, 3, $25-42$.

Harris, D. R. (Ed.). (1996). The origins and spread of agriculture and pastoralism in Eurasia. UCL Press.

Hein, A. (2016). The problem of typology in Chinese archaeology. Early China, 39, 21-52.

Hermes, T. R., Frachetti, M. D., Doumani Dupuy, P. N., Mar'yashev, A., Nebel, A., \& Makarewicz, C. A. (2019). Early integration of pastoralism and millet cultivation in Bronze Age Eurasia. Proceedings of the Royal Society B, 286(20191273), 1-9.

Honeychurch, W., \& Makarewicz, C. (2016). The archaeology of pastoral nomadism. Annual Review of Anthropology, 45, 341-359.

Horsley, T. J. (2015). The use of geophysical survey in archaeology. In R. A. Scott \& M. C. Buchmann (Eds.), Emerging trends in the social and behavioral sciences: An interdisciplinary, searchable, and linkable resource. https://doi.org/10.1002/9781118900772.etrds0356

Hou G. 侯光良, Liu F. 刘峰贵, Liu C. 刘翠华 \& Fang, X.方修绮. (2009). Zhongguo Quanxinshi Ganqing diqu gu wenhua bianqian de huanjing qudong中全新世甘青地区古文化变迁的环境驱动 (Prehistorical cultural transition forced by environmental change in mid-Holocene in Gansu-Qinghai region). Dizhi Xuebao地理学报 [Acta Geographica Sinica], 2009(64), 54-58.

Hou, J., Huang, Y., Zhao, J., Liu, Z., Colman, S., \& An, Z. (2016). Large Holocene summer temperature oscillations and impact on the peopling of the northeastern Tibetan Plateau. Geophysical Research Letters, 43(3), 1323-1330.

Hsu, K. J., \& Perry, C. A. (2002). Geophysical, archaeological, and historical evidence support a solaroutput model for climate change. Proceedings of the National Academy of Sciences USA, 97(23), 12433-12438.

$\mathrm{Hu}$, Q. 胡谦盈. (1980). Shilun Siwa wenhua试论寺洼文化 (A discussion of the Siwa culture). Wenwu Jikan文物集刊 [Cultural Relics Journal], 1980(2), 118-125.

Huang, C., Pang, J., Zhou, Y., Su, H., Zhang, Y., \& Wang, L. (2013). Palaeoenvironmental implications of the prehistorical catastrophes in relation to the Lajia Ruins within the Guanting Basin along the Upper Yellow River, China. The Holocene, 23(11), 1584-1595.

Huanghe Shuiku Kaogudui Gansu Fendui 黄河水库考古队甘肃分队. (1959). Gansu Yongjingxian Zhangjiazui yizhi fajue jianbao 甘肃永靖县张家咀遗址发掘简报 (Brief excavation report of Zhangjiazui in Yongjian county). Kaogu 考古 [archaeology], 1959(4), 181-184.

Hudson, M. J., Aoyama, M., Hoover, K. C., \& Uchiyama, J. (2012). Prospects and challenges for an archaeology of global environmental change. Wires Climate Change, 3, 313-328.

Izdebski, A., Holmgren, K., Weiberg, E., Stocker, S. R., Buentgen, U., Florenzano, A., Gogou, A., Leroy, S. A., Luterbacher, J., Martrat, B., \& Masi, A. (2016). Realising consilience: How better 
communication between archaeologists, historians and natural scientists can transform the study of past climate change in the Mediterranean. Quaternary Science Reviews, 136, 5-22.

Jaang, L. (2011). Long-distance interactions as reflected in the earliest Chinese bronze mirrors. In L. von Falkenhausen (Ed.), The Lloyd Cotsen study collection of Chinese bronze mirrors (Vol. 2, pp. 34-49). UCLA Cotsen Institute of Archaeology Press.

Jaang, L. (2015). The landscape of China's participation in the Bronze Age Eurasian network. Journal of World Prehistory, 28, 179-213.

Jacomet, S. (2006). Identification of cereal remains from archaeological sites. IPAS Basel University.

Jaffe, Y., Bar-Oz, G., \& Elenblum, R. (2019). Improving integration in societal consequences to climate change. Proceedings of the National Academy of Sciences USA, 201901538.

Jaffe, Y., Castellano, L., Shelach-Lavi, G., \& Campbell, R. (2020). Mismatches of scale in the application of paleoclimatic research to Chinese archaeology. Quaternary Research, 99, 14-33.

Jaffe, Y., \& Flad, R. (2018). Prehistoric globalizing processes in the Tao River Valley, Gansu, China? In N. Boivin \& M. Frachetti (Eds.), Globalization and the people without history (pp. 131-161). Cambridge University Press.

Jaffe, Y., \& Hein, A. (2020). Considering change with archaeological data: Reevaluating local variation in the role of the $\sim 4.2 \mathrm{k}$ BP event in Northwest China. The Holocene, 31(2), 169-182.

Jaffe, Y., Wei, Q., \& Zhao, Y. (2018). Foodways and the archaeology of colonial contact: Rethinking the Western Zhou expansion in Shandong. American Anthropologist, 120(1), 55-71.

Jiang, Y., 蒋宇超, Chen, G. 陈国科, \& Li S. 李水城. (2017). Gansu Xichengyi Yizhi 2010 Fuxuan Jieguo Fenxi 甘肃张掖西城驿遗址2010年浮选结果分析 (Report on the 2010 archaeobotanical remains from the site of Xichengyi in Gansu). Huaxia Kaogu 华夏考古 [Huaxia Archaeology], 2017(1), 62-68.

Joukowsky, M. S. (1986). A complete manual of field archaeology, tools and techniques of field work for archaeologists. Prentice Hall.

Kaufman, D., McKay, N., Routson, C., Erb, M., Dätwyler, C., Sommer, P., Heiri, O., \& Davis, B. (2020). Holocene global mean surface temperature: A multi-method reconstruction approach. Scientific Data, 7, 1-13.

Kintigh, K. W., Altschul, J. H., Beaudry, M. C., Drennan, R. D., Kinzig, A. P., \& Kohler, T. A. (2014). Grand challenges for archaeology. Proceedings of the National Academy of Sciences USA, 111(3), $879-880$.

Kvamme, K. L. (2006). Magnetometry: Nature's gift to archaeology. In J. Johnson (Ed.), Remote sensing in archaeology: An explicitly North American perspective (pp. 205-234). University of Alabama Press.

Leipe, C., Long, T., Sergusheva, E. A., Wagner, M., \& Tarasov, P. E. (2019). Discontinuous spread of millet agriculture in eastern Asia and prehistoric population dynamics. Science Advances, 5, eaax6225.

Li, F. (2006). Landscape and power in early China: The crisis and fall of the Western Zhou, 1045-771 $B C$. Cambridge University Press.

Li, H., An, C., Fan, W., Dong, W., Zhao, Y., \& Wang, H. (2015). Population history and its relationship with climate change on the Chinese Loess Plateau during the past 10,000 years. The Holocene, 25(7), 1144-1152.

Li, S., 李水城, Shui, T. 水涛 \& Wang, H. 王辉. (2010). Hexi zoulang shiqian kaogu diaocha baogao 河 西走廊史前考古调查报 告. (Report on the survey of prehistoric archaeology in the Hexi Corridor). Kaogu Xuebao 考古学报 [Acta Archaeologica Sinica], 2010(2), 229-264; 271-280.

Li, Z. 李志鹏, Brunson, K., \& Dai, L. 戴玲玲. (2014). Zhongyuan Diqu Xinshiqi Shidai Dao Qingtong Shidai Zaoqi yangmao Kaifa de Dongwu Kaoguxue Yanjiu (Wool exploitation from the Neolithic to the Early Bronze Age in the Central Plains). Disiji Yanjiu第四纪研究 [Quaternary Sciences], 34(1), 149-157.

Liang, C., Zhao, Y., Qin, F., Zheng, Z., Xiao, X., Ma, C., Li, H., \& Zhao, W. (2020). Pollen-based Holocene quantitative temperature reconstruction on the eastern Tibetan Plateau using a comprehensive method framework. Science China Earth Sciences, 63, 1144-1160.

Lin, M. 林梅村. (2016). Saiyima-Tu’erbinnuo wenhua yu shiqian Sichouzhilu 塞伊玛一图尔宾诺文化 与 史前丝绸之路 (Seima-Turbino culture and the proto-Silk Road). Wenwu 文物 [Cultural Relics], 2015(10), 49-63.

Lister, D., Jones, H., Oliveria, H., Petrie, C., Liu, X., Cockram, J., Kneale, C., \& Jones, M. (2018). Barley heads east: Genetic analyses reveal routes of spread through diverse Eurasian landscapes. PLoS ONE, 13(7), e0196652. 
Liu, F., \& Feng, Z. (2012). A dramatic climatic transition at 4000 Cal. Yr BP and its cultural responses in Chinese cultural domains. The Holocene, 22(10), 1181-1197.

Liu, L., \& Chen, X. (2012). The archaeology of China: From the Late Paleolithic to the Early Bronze Age. Cambridge University Press.

Liu, L., \& Xu, H. (2007). Rethinking Erlitou: Legend, history and Chinese archaeology. Antiquity, 81(314), 886-901.

Liu, F., Zhang, Y., \& Feng, Z. (2010). The impacts of climate change on the Neolithic cultures of GansuQinghai region during the late Holocene Megathermal. Journal of Geographic Sciences, 20(3), 417-430.

Liu, X., Lister, D. L., Zhao, Z., Petrie, C. A., Zeng, X., Jones, P. J., Staff, R. A., Pokharia, A. K., Bates, J., Singh, R. N., Weber, S. A., Matuzeviciute, G. M., Dong, G., Li, H., Lü, H., Jiang, H., Wang, J., Ma, J., Tian, D., Jin, G., Zhou, L., Wu, X., \& Jones, M. K. (2017). Journey to the east: Diverse routes and variable flowering times for wheat and barley en route to prehistoric China. PLoS One, 12(11), e0187405.

Long, T., Leipe, C., Jin, G., Wagner, M., Guo, R., Schröder, O., \& Tarasov, P. E. (2018). The early history of wheat in China from 14C dating and Bayesian chronological modelling. Nature Plants, 4 , $272-279$.

Lu, G. 路国权. (2013). Lu guoquan Jing, Luo, Wei heshangyou Xi Zhou wenhua bianjie ji xiangguan wenti chu lun路国权 泾、洛、渭河上游西周文化边界及相关问题初论 (The boundary of the Western Zhou culture in the upper reaches of the Jing, Luo, and Wei rivers and its relevant issues: The research of the history and culture in the marginal crescent transmission zone of culture). Kaogu yu Wenwu考古与文物 [Archaeology and Cultural Relics], 2013(3), 48-56.

Lu, L. 卢连成. (1985). Fufeng Liujia xian Zhou mudi pouxi lun xian Zhou wenhua 扶风刘家先周墓地 剖析-论先周文化 (Analysis of the pre-Zhou Liujia cemetery in Fufeng County). Kaogu yи Wenwu 考古与文物 [Archaeology and Cultural Relics], 1985(2), 1-12.

Ma, J. 马金否. (2013). Qinghai diqu qingtongqi shidai tudongmu de chubu yanjiu甘青地区青铜时代土 洞墓的初步研究 (Research on the early development of Bronze Age earthen catacomb-burials in Qinghai. Kaogu уи Wenwu考古与文物 [Archaeology and Cultural Relics], 2013(2), 32-40.

Ma, M., Dong, G., Jia, X., Wang, H., Cui, Y., \& Chen, F. (2016). Dietary shift after 3600 cal yr BP and its influencing factors in northwestern China: Evidence from stable isotopes. Quaternary Science Reviews, 145, 57-70.

Ma, M., Dong, G. H., Lightfoot, E., Wang, H., Liu, X. Y., Jia, X., Zhang, K., \& Chen, F. (2014). Human and faunal remains in the western Loess Plateau. Archaeometry, 56, 237-255.

Marcott, S. A., Shakun, J. D., Clark, P. U., \& Mix, A. C. (2013). A reconstruction of regional and global temperature for the past 11,300 Years. Science, 339(6124), 1198-1201.

Marshall, F., Reid, R. E., Goldstein, S., Storozum, M., Wreschnig, A., Hu, L., Kiura, P., Shahack-Gross, R., \& Ambrose, S. H. (2018). Ancient herders enriched and restructured african grasslands. Nature, 561(7723), 387-390.

Marston, J. M. (2011). Archaeological markers of agricultural risk management. Journal of Anthropological Archaeology, 30(2), 190-205.

McAnany, P., \& Yoffee, N. (2009). Questioning collapse: Human resiliency, vulnerability, and the aftermath of empire. Cambridge University Press.

Mei, J. (2003). Qijia and Seima-Turbino: The question of early contacts between northwest China and the Eurasian Steppe. Bulletin of the Museum of Far Eastern Antiquities, 75, 31-54.

Mei, J., Wang, P., Chen, K., Wang, L., Wang, Y., \& Liu, Y. (2015). Archaeometallurgical studies in China: Some recent developments and challenging issues. Journal of Archaeological Science, 56, 221-232.

Meller, H., Arz, H., Jung, R. \& Risch, R. (2015). 2200 BC-Ein Klimasturz als Ursache für den Zerfall der Alten Welt? Landesmüseum für Vorgeschichte.

Meltzer, D. (2015). The Great Paleolithic War: How science forged an understanding of America's Ice Age past. University of Chicago Press.

Miller, N., \& Smart, T. (1984). Intentional burning of dung as fuel: A mechanism for the incorporation of charred seeds into the archaeological record. Journal of Ethnobiology, 4, 15-28.

Minhexian Bowuguan 民和县博物馆. (2015). Qinghai Minhe xian Lajia yizhi de Xindian wenhua muzang 青海民和县喇家遗址的辛店文化墓葬 ) Xindian culture graves from the Lajia site in Minhe county, Qinghai). Kaogu 考古 [Archaeology], 2015(3), 115-120.

Mo, D., 莫多闻Li, F. 李非, \& Li, S. 李水城. (1996). Gansu Hulu he liuyu yuzhong Quanxinshi huanjing yanhua ji qidui renlei huodong de yinxiang甘肃葫芦河流域中全新世环境演化 及其对人类活动 
的影响 (A preliminary study on the palaeoenvironment of the middle Holocene in the Hulu River area in Gansu Province and its effects on human activity). Dili xuebao 地理学报 [Acta Geographica Sinica], 51(1), 59-69.

Nan, Y. 南玉泉. (1989). Xindian wenhua xulie jiqi yu Kayue, siwa wenhua de guanxi 辛店文化序列及 其与卡约、寺洼文化的关系 (Xindian culture assemblages and their relationships to the Kayue and Siwa cultures). In Yu [Weichao 俞伟超] (Ed). Kaogu leixingxue de lilu yu shijian 考古类型 学的理论与实践 [Chinese typology: Theory and practice], (pp.73-109). Wenwu Chubanshe文物 出版社.

Otárola-Castillo, E., \& Torquato, M. (2018). Bayesian statistics in archaeology. Annual Review of Anthropology, 47(1), 435-453.

Pederson, N., Hessl, A., Baatarbileg, N., Anchukaitis, K., \& Di Cosmo, N. (2014). Pluvials, droughts, the Mongol empire, and modern Mongolia. Proceedings of the National Academy of Sciences USA, 111(12), 4375-4379.

Pei, W. 裴文中. (1987). Gansu liqian kaogu baogao 甘肃史前 考古报告. (A report on Gansu prehistoric archaeology). In Pei, W. (Ed.), Pei Wenzhong liqian kaoguxue lunwenji 裴文中史前考古学论文集 [Pei Wenzhong's collected essays on prehistoric archaeology] (pp. 208-255). Wenwu Chubanshe 文物出版社.

Pines, Y., von Falkenhausen, L., Shelach, G., \& Yates, R. (2013). Birth of an empire: The state of Qin revisited. University of California Press.

Plog, S., Plog, F., \& Wait, W. (1978). Decision making in modern surveys. In M. B. Schiffer (Ed.), Advances in archaeological method and theory (pp. 3823-4421). Academic Press.

Qinghaisheng Wenwu Guanlichu Kaogudui 青海省文物管理處考古隊, \& Zhongguo Shehui Kexueyuan Kaogu Yanjiusuo 中國社會科學院考古研究所. (1984). Qinghai Liuwan: Ledu Liuwan yuanshi shehui mudi 青海柳湾—乐都柳湾原始社会墓地 [The cemetery of early Liuwan society, Liuwan, Qinghai]. Beijing: Wenwu Chubanshe 文物出版社.

Qinghaisheng Wenwu Kaogudui 青海省文物考古队. (1986). Qinghai Huzhu tuzu zizhixian zongzhai Machang, Qijijia, Xindian wenhua muzang 青海互助土族自治县总寨马厂、齐家、辛店文化墓 葬 (The Machang, Qijia and Xindina culture cemetery of Huzhu in Zizhi county, Qinghai). Kaogu 考古 [Archaeology], 1986(4), 306-317.

Qinghaisheng Wenwu Guanlisuo 青海省文物管理所. (1995). Qinghai Minhe Hetaozhuang Xiaohandi mudi fajue jianbao 青海民和核桃小旱地墓地发掘简报 (Brief excavation report of Hetaozhuang Xiaohandi cemetery, Minhe, Qinghai). Kaogu Yu Wenwu考古与文物 [Archaeology and Cultural Relics], 1995(2), 1-12.

Railsback, L. B., Liang, F., Brook, G., Voarintsoa, N. R. G., Sletten, H. R., Marais, E., Hardt, B., Cheng, H., \& Edwards, R. L. (2018). The timing, two-pulsed nature, and variable climatic expression of the 4.2 ka event: A review and new high-resolution stalagmite data from Namibia. Quaternary Science Reviews, 186, 78-90.

Redman, C. (2005). Resilience theory in archaeology. American Anthropologist, 107(1), 70-77.

Ren, R. 任瑞波. (2016). Xibei diqu caitao wenhua yanjiu 西北地區彩陶文化研究 [Study on the Painted-Pottery Culture of Northwest China]. Ph.D. Dissertation, Archaeology, Jilin University, Changchun.

Ren, R. 任瑞波. (2017). Lun Lajia yizhi ‘Xindian wenhua’ muzang de wenhua guishu 论喇家遗址’ 辛店 文化'墓葬的文化归属 (Reevaluating the identification of Xindian culture graves at the Lajia site). Kaogu 考古 [Archaeology], 2017(5), 114-120.

Ren, R. 任瑞波. (2019). Lun Xindian wenhua de fenqi yu niandai 论辛店文化的分期与年代 [On the periodization and date of the Xindian culture]. Kaogu Xuebao 考古學報 [Archaeological Research], 2019(4), 439-460.

Shelach, G. (2009). Prehistoric societies on the northern frontiers of China: Archaeological perspectives on identity formation and economic change during the first millennium BCE. Equinox.

Shelach, G., \& Jaffe, Y. (2014). The earliest states in China: A long-term trajectory approach. Journal of Archaeological Research, 22, 327-364.

Shui, T. 水涛. (1989). Guanyu Siwa wenhua yanjiu de jige wenti 关于寺哇文花研究的几个问题 (Some problems concerning the study of the Siwa Culture). Xibei Shidi 西北史地 [Historical and geographical review of Northwest China], 1989(3), 119-114.

Shui, T. 水涛. (2001). Ganqing qingtongqi shidai de wenhua jieguo he jingji tai yanjiu diqu甘青青铜 器时代的文化结构和经济态研究地区 (A study of cultural structure and economic form in the Bronze Age of Gansu and Qinghai). In Shui Tao [水涛] (Ed), 中国西北地区青铜时代考古论集 
[Collected essays on the Bronze Age archaeology of China's northwestern regions] (pp. 193-322). Beijing: Kexue Chubanshe科学出版社.

Sommarström, B. (1956). The site of Ma-Kia-Yao, Bulletin of the Museum of Far Eastern Antiquities, 28. Museum of Far Eastern Antiquities.

Spengler, R., Frachetti, M., Doumani, P., Rouse, L., Cerasetti, B., Bullion, E., \& Mar'yashev, A. (2014). Early agriculture and crop transmission among Bronze Age mobile pastoralists of Central Eurasia. Proceedings of the Royal Society B, 281, 20133382.

Spengler, R. N., III., \& Mueller, N. (2019). Grazing animals drove domestication in grain crops. Nature Plants, 5, 656-662.

Su, K., \& Kidder, T. (2019). Humans and climate change in the middle and lower Yellow River of China. Quaternary International, 521, 111-117.

Tainter, J. (2006). Social complexity and sustainability. Ecological Complexity, 3, 91-103.

Tan, L., Cai, Y., Cheng, H., Edwards, R., Gao, Y., Xu, H., Zhang, H., \& An, Z. (2018). Centennial- to decadal-scale monsoon precipitation variations in the upper Hanjiang River region, China over the past 6650 years. Earth and Planetary Science Letters, 482, 580-590.

Ur, J. A., Karsgaard, P., \& Oates, J. (2011). The spatial dimensions of early Mesopotamian urbanism: The Tell Brak suburban survey, 2003-2006. Iraq, 73, 1-19.

Ventresca Miller, A., \& Makarewicz, C. (2019). Intensification in pastoralist cereal use coincides with the expansion of trans-regional networks in the Eurasian Steppe. Scientific Reports, 9(1), 8363.

Ventresca Miller, A., Spengler, R., Haruda, A., Miller, B., Wilkin, S., Robinson, S., Roberts, P., \& Boivin, N. (2020). Ecosystem engineering among ancient pastoralists in northern Central Asia. Frontiers in Earth Science, 8, 1-14.

Wagner, M., Tarasov, P., Hosner, P., Fleck, A., Ehrich, R., Chen, X., \& Leipe, C. (2013). Mapping of the spatial and temporal distribution of archaeological sites of northern China during the Neolithic and Bronze Age. Quaternary International, 290-291, 344-357.

Wang, H. 王辉. (2012). Ganqing diqu Xinshiqi-Qingtongqi shidai kaoguxue wenhua de puxi yu geju甘 青地区新石器 - 青铜时代考古学文化的谱系与格局 [Variant sand patterns in the Neolithic and Bronze Age cultures of the Gansu-Qinghai region]. Kaoguxue Jikan考古學研究 [Archaeological Research], 2012(9), 219-243.

Wang, Y. (2017). Identifying the beginnings of sheep husbandry in western China. Ph.D. Dissertation. Cambridge: University of Cambridge.

Wang, Y., Cheng, H., Edwards, R., He, Y., Kong, X., An, Z., Wu, J., Kelly, M., Dykoski, C., \& Li, X. (2005). The Holocene Asian monsoon: Links to solar changes and North Atlantic climate. Science, 308, 854-857.

Womack, A., Flad, R., Zhou, J., Brunson, K., Toro, F., Su, X., Hein, A., d'Alpoim Guedes, J., Jin, G., Wu, X., \& Wang, H. (2021). The Majiayao to Qijia transition: Exploring the intersection of technological and social continuity and change. Asian Archaeology, 4, 95-120.

Womack, A., Horsley, T., Wang, H., Zhou, J., \& Flad, R. (2019a). Assessing site organization and development using geophysical prospection at Dayatou, Gansu, China. Journal of Archaeological Science: Reports, 27, 1-12.

Womack, A., Jaffe, Y., Zhou, J., Hung, L., Wang, H., Li, S., Chen, P., \& Flad, R. (2017). Mapping Qijiaping: New work on the type-site of the Qijia Culture (2300-1500 B.C.) in Gansu Province, China. Journal of Field Archaeology, 42, 488-502.

Womack, A., Wang, H., Zhou, J., \& Flad, R. (2019b). A petrographic analysis of clay recipes in Late Neolithic north-western China: Continuity and change. Antiquity, 93(371), 1161-1177.

Wu, Q., Zhao, Z., Liu, L., Granger, D., Wang, H., Cohen, D., Wu, H., Ye, M., Bar-Yosef, O., Lu, B., Zhang, J., Zhang, P., Yuan, D., Qi, W., Cai, L., \& Bai, S. (2016). Outburst flood at 1920 BCE supports historicity of China's Great Flood and the Xia dynasty. Science, 353, 579-582.

Wu, W., Dai, J., Zhou, J., \& Ge, Q. (2017). Comment on 'Outburst flood at 1920 BC supports historicity of China's Great Flood and the Xia dynasty.' Science, 355, 1382.

Wu, W., \& Liu, T. (2004). Possible role of the 'Holocene Event 3' on the collapse of Neolithic cultures around the Central Plain of China. Quaternary International, 117(1), 153-166.

Wu, Z., \& Raven, P. (2006). Missouri Botanical Gardens. Flora of China. Missouri Botanical Gardens.

Xia, N. 夏鼎. (1949). Lintao Siwashan fajue ji 临洮寺洼山发掘记 (Report on the excavations at Siwashan in Lintao). Zhongguo Kaogu Xuebao 中國考古學報 [Chinese Archaeological Reports], 1949(4), 71-187.

Xie, D. 谢端琚. (1985). Lüelun Xindian wenhua 略論辛店文化 (Discussing Xindian culture). Wenwu ziliao congkan 文物資料叢刊 [Collected reports on cultural relics], 1985(9), 59-76. 
Xie, D. 谢端琚. (2002). Ganqing Diqu shiqian kaogu甘青地區史前考古 [Prehistoric archaeology of the Qanqing region]. Wenwu Chubanshe 文物出版社.

Xu, H. 许宏. (2009). Zui zao de Zhonguo 最早的中国 [Earliest China]. Beijng Kexue Chubanshe科学 出版社.

Xu, X. 许新国. (1988). Shilun Kayue de leixing yu fenqi 试论卡约文化的类型与分期 (The typology and periodization of the Kayue culture). Qinghai Wenwu 青海文物 [Qinghai Cultural Relics], 1988(1), 19-14.

Yan, H. 阎宏东. (2010). Shenmu Shimao yizhi taoqi fenxi [神木石峁遗址陶器分析] Analysis of pottery at the Shimao site, Shenmu county. Wenbo 文博 [Relics and Museology], 2010(6), 3-9.

Yan, W. 严文明. (1978). Gansu caitao de yuanliu 甘肅彩陶的源流 (The development of Gansu painted pottery). In Yan Wenming 严文明 (Ed.), Yangshao wenhua yanjiu 仰韶文化研究 [Research on the Yangshao Culture] (pp. 309-327). Wenwu Chubanshe 文物出版社.

Yang, Y. 杨颖. (2015). Hehuang diqu Jindankou he Liajiaping Qijia wenhua yizhi zhiwu da yicun fenxi 河湟地区金禅口和李家坪齐家文化遗址植物大遗存分析 (Report on the macrobotanical remains from the Jiandankou and Lijiaping Qijia culture sites), Lanzhou: Lanzhou University兰州 大学资源环境学院.

Yang, Y., Ren, L., Dong, G., Cui, Y., Liu, R., Chen, G., Wang, H., Wilkin, S., \& Chen, F. (2019a). Economic change in the prehistoric Hexi Corridor (4809-2200BP), northwest China. Archaeometry, 61(4), 957-976.

Yang, Y., Zhang, S., Oldknow, C., Qiu, M., Chen, T., Li, H., Cui, Y., Ren, L., Chen, G., Wang, H., \& Dong, G. (2019b). Refined chronology of prehistoric cultures and its implication for re-evaluating human-environment relations in the Hexi Corridor, northwest China. Science China Earth Sciences, 62, 1578-1590.

You, Y.尤悦, Lu P.吕鹏, Wang, J.王建新, Ma, J.马健 \& Ren, M.任萌. (2016). Xinjiang diqu Jjayang mianyang de chuxian ji zaoqi liyong新疆地区家养绵羊的出现及早期利用 (The beginnings and early use of domestic sheep in Xinjiang). Kaogu考古[Archaeology], 2016(12), 104-114.

Zeder, M., \& Lapham, H. (2010). Assessing the reliability of criteria used to identify postcranial bones in sheep, Ovis, and goats, Capra. Journal of Archaeological Science, 37(11), 2887-2905.

Zeder, M., \& Pilaar, S. (2010). Assessing the reliability of criteria used to identify mandibles and mandibular teeth in sheep, Ovis, and goats, Capra. Journal of Archaeological Science, 37(2), 225-242.

Zhang, C. 张晨. (2013). Qinghai Minhe Lajia yizhi fauxuan yixun fenxi 青海民和喇家遗址浮选植物 遗存分析 (Report on the archaeobotanical remains from the Lajia site in Minhe county Qinghai). Masters Thesis. Xibei University Department of Cultural Heritage.

Zhang, H., Cheng, H., Cai, Y., Spotl, C., Kathayat, G., Sinha, A., Edwards, R., \& Tan, L. (2018a). Hydroclimatic variations in southeastern China during the $4.2 \mathrm{ka}$ event reflected by stalagmite records. Climate Past, 14, 1805-1817.

Zhang, J., Lu, H., Jia, P., Flad, R., Wu, N., \& Betts, A. (2017). Cultivation strategies at the ancient Luanzagangzi settlement on the easternmost Eurasian steppe during the late Bronze Age. Vegetation History and Archaeobotany, 26(5), 505-512.

Zhang, X. 张小虎. (2012). Qinghai Guantong pandi zhiwu kaogu diaocha shouhuo ji xianguan wenti 青海官亭盆地植物考古调查收获及相关问题. (The results and relevant issues of the archaeobotanical investigation of the Guanting basin, Qinghai Province). Kaogu yu Wenwu考古与文物 [Archaeology and Cultural Relics], 2012(3), 26-33.

Zhang, X. 张学正 \& Pu, C. 蒲朝绂. (1985). Yongjing Maluyuan he Linxia xian Lianhuatai Xindian wenhua yizhi 永靖马路塬和临夏县莲花台辛店文化遗址 (The Xindian sites of Maluyuan of Yongjian county and Lianhuatai of Linxia county). Zhongguo kaoguxue nianji 中国考古学年级 1985 [Chinese Archaeological almanac 1985]. Wenwu Chubanshe 文物出版社.

Zhang, Y., Huang, C., Pang, J., Guo, Y., \& Zhou, Q. (2018b). Identification of the prehistoric catastrophes at the Lajia ruins using micromorphological analysis within the Guanting Basin, Minhe County, Qinghai Province. Archaeological and Anthropological Sciences, 10(3), 711-723.

Zhao, H. 赵化成. (1989). Gansu dongbu Qin he Qian Rong wenhua de kaoguxue tansuo甘肃东部秦和 差戎文化的考古学探索 (An archaeological study of the Qin and Qian Rong cultures in eastern Gansu). In Yu, W. 俞伟超 (Ed.), Kaogu leixingxue de lilun yu shijian考古类型学的理论与实践 [Chinese typology: Theory and practice] (pp. 145-176). Wenwu Chubanshe文物出版社.

Zhao, Z. 赵志军. (2003). Qinghai Lajia yizhi changshixiang fuxuan jieguo 青海喇家遗址尝试性浮 选的结果 (Results of experimental flotation carried out at the Lajia site in Qinghai). Zhongguo Wenwubao中国文物报 [Chinese Cultural Relics], 2003(9), 7. 
Zhao, Z. 赵志军 (2010). Zhiwu kaogu: Lilun, fangfa he shixian植物考古学: 理论, 方法和实 现 [Paleoethnobotany: Theory, methods, practice]. Beijing: Science Press科学出版社.

Zhao, Y., Yu, Z., Chen, F., Zhang, J., \& Yang, B. (2009). Vegetation response to Holocene climate change in monsoon-influenced region of China. Earth Science Reviews, 97, 242-256.

Zhongguo Shehui Kexuyuan Kaogu Yanjiusuo Gansu Gongzuodui 中国社会科学院考古研究所甘肃工 作队. (1980a). Gansu yongjing Zhangjiazui yu Jijiachuan yizhi de fajue甘肃永靖张家咀与姬家 川遗址的发掘 (Excavations at the sites of Zhangjiazui and Jijiachuan in Yongjing, Gansu). Kaogu Xиebao 考古学报 [Acta Archaeologica Sinica], 1980(2), 187-220.

Zhongguo Shehui Kexuyuan Kaogu Yanjiusuo Gansu Gongzuodui 中国社会科学院考古研究所甘肃工 作队. (1980b). Gansu Linxia Lianhuatai Xindian wenhua yizhi 甘肅臨夏蓮花台辛店文化遺址 (The Xindian culture site of Lianhuatai in Linxia, Gansu). Kaogu考古 [Archaeology], 1980(4), 296-310.

Zhongguo Shehui Kexuyuan Kaogu Yanjiusuo 中国社会科学院考古研究所. (1999). Shizhaocun yu Xishanping 师赵村与西山坪 [Shizhaocun and Xishanping]. Beijing: Zhongguuo Dabaike Quanshu Chubanshe 中国大百科全书出版社.

Zhongguo Shehui Kexueyuan Kaogu Yanjiusuo中国社会科学院考古研究所. (2003). Zhongguo kaoguxue-Xia Shang juan 中國考古學——夏商卷 [Chinese Archaeology: The Xia \& Shang volume]. Beijing: Zhongguo Dabaike Quanshu Chubanshe中国大百科全书出版社.

Zhuang, Y., \& Kidder, T. (2014). Archaeology of the Anthropocene in the Yellow River region, China, 8000-2000 Cal. BP. The Holocene, 24(11), 1602-1623.

Publisher's Note Springer Nature remains neutral with regard to jurisdictional claims in published maps and institutional affiliations.

\section{Authors and Affiliations}

\section{Yitzchak Jaffe ${ }^{1} \cdot$ Anke Hein $^{2} \cdot$ Andrew Womack $^{3} \cdot$ Katherine Brunson $^{4}$. Jade d'Alpoim Guedes ${ }^{5}$. Rongzhen Guo ${ }^{6}$. Jing Zhou ${ }^{7}$. Jada $\mathrm{Ko}^{8}$. Xiaohong Wu ${ }^{9} \cdot$ Hui Wang ${ }^{10} \cdot$ Shuicheng $\mathrm{Li}^{11} \cdot$ Rowan Flad $^{8}$}

1 Department of Archaeology, Zinman Institute of Archaeology, University of Haifa, 199 Aba-Hushi Avenue, 3498838 Haifa, Israel

2 Institute of Archaeology, Oxford University, 36 Beaumont St, Oxford OX1 2PG, UK

3 Department of Asian Studies, Furman University, Room 224c, Furman Hall, Greenville, SC 29613, USA

4 Archaeology Program, Wesleyan University, 284 High Street, Middletown, CT 06459, USA

5 Scripps Institution of Oceanography, University of California, San Diego, Sverdrup Hall, Rm \# 1255, 8615 Kennel Way, La Jolla, CA 92037-0212, USA

6 Department of Archaeology, Shandong University, 27 Shanda South Road, Jinan 250100, Shandong, China

7 Gansu Provincial Institute of Archaeology, Chengguan District, Lanzhou 730015, Gansu, China

8 Department of Anthropology, Harvard University, 11 Divinity Ave., Peabody Museum, Cambridge, MA 02143, USA

9 School of Archaeology and Museology, School of Archaeology and Museology, Peking University, No. 5 Yiheyuan Road, Beijing 100871, China

10 Department of Cultural Heritage and Museology, Handan Campus, Fudan University, Northern Triangle Area, No1 building, 220 Handan Road, Shanghai 200433, China

11 Sichuan University, 29 Wangjiang Road, Chengdu 610064, Sichuan, China 